\title{
Food sources of carbohydrates in a European cohort of adults
}

\author{
E Wirfält ${ }^{1, *}$, A McTaggart ${ }^{2}$, V Pala ${ }^{3}$, B Gullberg ${ }^{4}$, G Frasca $^{5}$, S Panico $^{6}$, \\ HB Bueno-de-Mesquita 7 , PHM Peeters ${ }^{8}$, D Engeset ${ }^{9}, G$ Skeie $^{9}$, MD Chirlaque ${ }^{10}$, \\ P Amiano ${ }^{11}$, E Lundin ${ }^{12}$, A Mulligan ${ }^{2}$, EA Spencer ${ }^{13}, \mathrm{~K}$ Overvad $^{14}$, A Tiønneland ${ }^{15}$, \\ F Clavel-Chapelon ${ }^{16}$, J Linseisen ${ }^{17}$, U Nöthlings ${ }^{18}$, E Polychronopoulos $^{19}, \mathrm{~K} \mathrm{Georga}^{20}$, \\ UR Charrondière ${ }^{21}$ and $N$ Slimani ${ }^{21}$
}

'Department of Medicine, Lund University, Malmö, SE-20502 Sweden: ${ }^{2}$ Department of Public Health and Primary Care, School of Clinical Medicine, University of Cambridge, UK: ${ }^{3}$ Department of Epidemiology, National Cancer Institute, Milan, Italy: ${ }^{4}$ Department of Community Medicine, Lund University, Malmö, Sweden: ${ }^{5}$ Cancer Registry, 'Civile - M.P. Arezzo' Hospital, Ragusa, Italy: ${ }^{\circ}$ Department of Clinical and Experimental Medicine, Federico II University, Naples, Italy: ${ }^{7}$ Centre of Chronic Diseases Epidemiology, National Institute of Public Health and the Environment, Bilthoven, The Netherlands: ${ }^{8}$ Julius Center for General Practice and Patient Oriented Research,

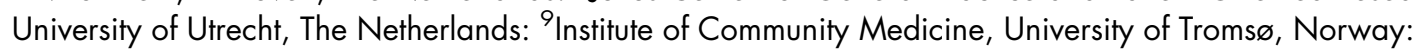
${ }^{10}$ Department of Epidemiology, Regional Health Council, Murcia, Spain: ${ }^{11}$ Public Health Division of Gipuzkoa, Department of Health of the Basque Government, San Sebastian, Spain: ${ }^{12}$ Department of Public Health and Clinical Medicine, Umeå University, Sweden: ${ }^{13}$ Cancer Research UK, Epidemiology Unit, University of Oxford, UK:

${ }^{14}$ Department of Epidemiology and Social Medicine, Aarhus University, Denmark: ${ }^{15}$ Danish Cancer Society, Institute of Cancer Epidemiology, Copenhagen, Denmark: ${ }^{16}$ INSERM, E3N-EPIC Group, Institute Gustave Roussy, Villejuif, France: ${ }^{17}$ Division of Clinical Epidemiology, German Cancer Research Centre, Heidelberg, Germany: ${ }^{18}$ Department of Epidemiology, German Institute of Human Nutrition, Potsdam-Rehbrücke, Germany: ${ }^{19}$ National School of Public Health, Athens, Greece: ${ }^{20}$ Department of Hygiene and Epidemiology, School of Medicine, University of Athens, Greece: ${ }^{21}$ International Agency for Research on Cancer, Lyon, France

\begin{abstract}
Objective: To describe the average consumption of carbohydrate-providing food groups among study centres of the European Prospective Investigation into Cancer and Nutrition (EPIC).

Methods: Of the 27 redefined EPIC study centres, 19 contributed subjects of both genders and eight centres female participants only (men, $n=13031$; women, $n=$ 22924 , after exclusion of subjects under 35 and over 74 years of age from the original 36900 total). Dietary data were obtained using the 24-hour recall methodology using the EPIC-SOFT software. The major sources of dietary carbohydrate were identified, and 16 food groups were examined.

Results: The 10 food groups contributing most carbohydrate were bread; fruit; milk and milk products; sweet buns, cakes and pies; potato; sugar and jam; pasta and rice; vegetables and legumes; crispbread; and fruit and vegetable juices. Consumption of fruits as well as vegetables and legumes was higher in southern compared with northern centres, while soft drinks consumption was higher in the north. Italian centres had high pasta and rice consumption, but breakfast cereal, potato, and sweet buns, cakes and pies were higher in northern centres. In Sweden, lower bread consumption was balanced with a higher consumption of crispbread, and with sweet buns, cakes and pies. Overall, men consumed higher amounts of vegetables and legumes, bread, soft drinks, potatoes, pasta and rice, breakfast cereal and sugar and jam than women, but fruit consumption appeared more frequent in women.

Conclusion: The study supports the established idea that carbohydrate-rich foods chosen in northern Europe are different from those in the Mediterranean region. When comparing and interpreting diet-disease relationships across populations, researchers need to consider all types of foods.
\end{abstract}

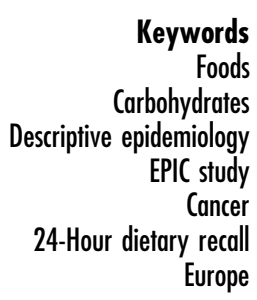

eywords

oods

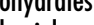

PIC study

Cancer Europe
Carbohydrates contribute a major proportion of dietary energy in most populations ${ }^{1,2}$. The influences of carbohydrate-rich diets on health and disease may, however, diverge substantially depending on the specific types and food sources of carbohydrate. Dietary carbo- hydrates are defined as naturally occurring sugars, added sugars, starch, resistant starch and dietary fibre/non-starch polysaccharides (NSP). Plant foods contribute not only dietary carbohydrates, but also a whole array of essential micronutrients and food components, generally identified 
as protective agents with respect to cancer risk $^{2,3}$. For instance, soy products, legumes, whole grains and flax, with a high content of isoflavones and lignans ${ }^{4,5}$, have been related to decreased cancer risk, especially breast cancer $^{6}$. Most refined food products that contribute carbohydrates will provide only negligible amounts of these food components.

The evidence linking carbohydrates to the risk of disease is inconsistent. Several factors influence the physiological response after carbohydrate ingestion and these factors may explain some inconsistencies. Experimental studies indicate that both the type of carbohydrate and the physical properties of the specific food item ${ }^{7,8}$ influence the postprandial glucose and insulin response (i.e. the Glycaemic Index (GI) and Insulin Index). Thus not only the type of carbohydrate ingested ${ }^{7,9}$, but also factors such as the refinement of foods and the physical and chemical properties of carbohydrates at the moment of consumption, could potentially influence the development of disease ${ }^{8}$. For instance, observational studies indicate that high-GI diets are related to increased risk of non-insulin-dependent diabetes mellitus (NIDDM) both in men and women ${ }^{10,11}$, and clinical trials show that low-GI energy-restricted diets, compared with similar high-GI diets, favour long-term weight reduction ${ }^{12}$. It has been hypothesised that chronic hyperinsulinaemia may be a link between dietary factors (other than simply a sum of nutrients) and the development of high-risk steroid hormone profiles and increased breast cancer incidence ${ }^{13}$. Case-control studies ${ }^{14,15}$, and two large prospective

Table 1 Food groups contributing carbohydrates in the European Prospective Investigation into Cancer and Nutrition (EPIC) study populations

\begin{tabular}{|c|c|c|c|c|}
\hline \multirow[b]{2}{*}{ Food groups in EPIC-SOFT } & \multirow[b]{2}{*}{ Final food groups } & \multicolumn{2}{|c|}{$\begin{array}{l}\text { Average amount } \\
\text { of food }\left(\mathrm{g} \mathrm{day}^{-1}\right)\end{array}$} & \multirow{2}{*}{$\begin{array}{c}\text { Contribution by each food group, } \\
\% \text { of total carbohydrate }\end{array}$} \\
\hline & & Men & Women & \\
\hline Potatoes & Potatoes & 99 & 66 & 6.8 \\
\hline $\begin{array}{l}\text { Vegetables } \\
\text { Legumes }\end{array}$ & Vegetables \& legumes & 187 & 176 & 4.1 \\
\hline Fruits & Fruits & 225 & 230 & 12.9 \\
\hline \multicolumn{5}{|l|}{$\begin{array}{l}\text { Milk, milk beverages } \\
\text { Yoghurt } \\
\text { Fromage blanc }\end{array}$} \\
\hline $\begin{array}{l}\text { Cream desserts, etc. } \\
\text { Dairy and non-dairy creams } \\
\text { Milk for coffee and creamers } \\
\text { Ice cream \& water ice }\end{array}$ & Milk \& milk products & 266 & 260 & 8.4 \\
\hline Flour, etc. & - & & & \\
\hline Pasta, rice & Pasta \& rice & 65 & 44 & 6.0 \\
\hline Bread & Bread & 148 & 100 & 26.6 \\
\hline Crispbread, rusks & Crispbread & 10 & 8 & 2.9 \\
\hline $\begin{array}{l}\text { Breakfast cereals } \\
\text { Dough, pastry, pizza }\end{array}$ & Breakfast cereals & 15 & 10 & 2.0 \\
\hline Cakes, pies, pastries & Sweet buns, cakes \& pies & 44 & 43 & 7.3 \\
\hline Dry cakes, biscuits & Sweet biscuits & 8 & 9 & 2.5 \\
\hline $\begin{array}{l}\text { Salty biscuits } \\
\text { Miscellaneous, snacks }\end{array}$ & Salty biscuits \& snacks & 5 & 5 & 1.1 \\
\hline Processed meats & - & & & \\
\hline Fish products & - & & & \\
\hline Sugar, honey, jam, syrup & Sugar \& jam & 23 & 16 & 6.2 \\
\hline Chocolate, candy bars & Chocolates & 6 & 7 & 1.6 \\
\hline Confectionery, non-chocolate & Sweets & 4 & 4 & 1.2 \\
\hline Dessert sauces & - & & & \\
\hline Non-alcoholic beverages & - & & & \\
\hline Fruit and vegetable juices & Fruit \& vegetable juices & 65 & 68 & 2.8 \\
\hline Soft drinks & Soft drinks & 105 & 66 & 2.5 \\
\hline Coffee, tea and herbal teas & - & & & \\
\hline Soups & - & & & \\
\hline Sauces & - & & & \\
\hline
\end{tabular}


Table 2a Mean consumption of bread and crispbread by men $(n=13031)$ in 19 European Prospective Investigation into Cancer and Nutrition (EPIC) centres

\begin{tabular}{|c|c|c|c|c|c|c|c|}
\hline \multirow[b]{3}{*}{ Country and centre } & \multirow[b]{3}{*}{ Total $n$} & \multicolumn{3}{|c|}{ Bread $\left(\mathrm{g} \mathrm{day}^{-1}\right)$} & \multicolumn{3}{|c|}{ Crispbread $\left(\mathrm{g} \mathrm{day}^{-1}\right)$} \\
\hline & & \multirow[b]{2}{*}{ Crude mean } & \multicolumn{2}{|c|}{ Adjusted* } & \multirow[b]{2}{*}{ Crude mean } & \multicolumn{2}{|c|}{ Adjusted $^{*}$} \\
\hline & & & Mean & SEM & & Mean & SEM \\
\hline \multicolumn{8}{|l|}{ Greece } \\
\hline Greece & 1312 & 181.6 & 173.6 & 3.0 & 12.6 & 14.2 & 0.6 \\
\hline \multicolumn{8}{|l|}{ Spain } \\
\hline Granada & 214 & 149.6 & 148.8 & 7.4 & 4.0 & 3.8 & 1.5 \\
\hline Murcia & 243 & 156.3 & 156.3 & 6.9 & 5.8 & 6.5 & 1.4 \\
\hline Navarra & 444 & 179.2 & 178.8 & 5.1 & 2.6 & 2.7 & 1.1 \\
\hline San Sebastian & 490 & 150.9 & 147.4 & 4.9 & 4.3 & 5.1 & 1.0 \\
\hline Asturias & 386 & 139.6 & 137.1 & 5.5 & 6.2 & 6.8 & 1.1 \\
\hline \multicolumn{8}{|l|}{ Italy } \\
\hline Ragusa & 168 & 184.0 & 185.3 & 8.3 & 7.4 & 7.6 & 1.7 \\
\hline Florence & 271 & 164.8 & 165.2 & 6.6 & 7.3 & 7.3 & 1.3 \\
\hline Turin & 677 & 156.4 & 154.8 & 4.2 & 20.3 & 20.4 & 0.9 \\
\hline Varese & 328 & 138.3 & 144.3 & 6.0 & 6.7 & 7.4 & 1.2 \\
\hline \multicolumn{8}{|l|}{ Germany } \\
\hline Heidelberg & 1033 & 147.5 & 141.0 & 3.4 & 1.3 & 1.5 & 0.7 \\
\hline Potsdam & 1235 & 161.6 & 159.1 & 3.1 & 2.7 & 2.7 & 0.6 \\
\hline \multicolumn{8}{|l|}{ The Netherlands } \\
\hline Bilthoven & 1024 & 173.6 & 167.7 & 3.5 & 2.9 & 3.9 & 0.7 \\
\hline \multicolumn{8}{|l|}{ United Kingdom } \\
\hline General population & 404 & 122.8 & 124.6 & 5.4 & 3.4 & 3.4 & 1.1 \\
\hline 'Health-conscious' & 114 & 145.9 & 144.0 & 10.1 & 3.0 & 2.9 & 2.1 \\
\hline \multicolumn{8}{|l|}{ Denmark } \\
\hline Copenhagen & 1356 & 174.8 & 177.4 & 2.9 & 2.5 & 2.2 & 0.6 \\
\hline Aarhus & 567 & 190.7 & 195.2 & 4.5 & 1.9 & 2.2 & 0.9 \\
\hline \multicolumn{8}{|l|}{ Sweden } \\
\hline Malmö & 1421 & 105.0 & 112.6 & 3.0 & 9.9 & 8.6 & 0.6 \\
\hline Umeå & 1344 & 74.8 & 77.0 & 3.0 & 40.7 & 41.1 & 0.6 \\
\hline
\end{tabular}

SEM - standard error of the mean.

${ }^{*}$ Adjusted for age and standardised for day of the week and season.

studies that have related NIDDM to colon cancer incidence ${ }^{16,17}$, imply that insulin resistance is a putative risk factor for colon cancers. Furthermore, it has been hypothesised that the intestinal flora in the colon uses, in addition to NSP, some component of starch as a substrate. In fact, the consumption of resistant starch leads to an increase in faecal bulk and butyrate production as well as a decrease in secondary bile acids in faeces ${ }^{18-20}$. These factors are all potentially related to a decrease in colon cancer risk ${ }^{20}$

In addition, studies suggest that added sucrose may have specific disadvantageous effects. An experimental study in rats recently found that high intakes of sucrose were associated with a higher frequency of GC to AT mutations in the $c I I$ transgene of the colonic epithelium ${ }^{21}$. Also, an epidemiological study has observed similar mutations in individuals with colon cancer and high-GI diets $^{22}$. Moreover, fibre-rich diets, especially those high in cereal fibre, prevent constipation and may help control energy intake and body weight by promoting satiety by slowing gastric emptying ${ }^{23}$. Obesity and positive energy balance have been identified as potential risk factors for many cancers ${ }^{24,25}$. Some researchers argue that there is sufficient evidence to link the dietary proportions of macronutrients to the development of obesity (especially high intakes of saturated fat and low intakes of fibre-rich foods), but others only agree that excess of energy intake over expenditure is important ${ }^{2}$.

Information about the distribution of different types of carbohydrate-rich foods across European populations would therefore not only illustrate how dietary habits differ in Europe, but also could assist in the further development of hypotheses on the relationships between diet, cancer and other chronic diseases. The primary aim of this paper is to describe, separately for men and women, the average consumption of carbohydrateproviding food groups across study centres of the European Prospective Investigation into Cancer and Nutrition (EPIC).

\section{Methods and materials}

The EPIC multi-centre cohort study is investigating the relationship between diet and cancer in 10 Western European countries: Denmark, France, Germany, Greece, Italy, Norway, Spain, Sweden, The Netherlands and the $\mathrm{UK}^{26}$. The study population consists of 519978 mainly middle-aged men and women. Of the 27 study centres examined in this paper, 19 centres contributed subjects of both genders and eight centres female participants only. In 
Table $\mathbf{2 b}$ Mean consumption of sweet buns, cakes and pies, and sweet biscuits by men $(n=13031)$ in 19 European Prospective Investigation into Cancer and Nutrition (EPIC) centres

\begin{tabular}{|c|c|c|c|c|c|c|c|}
\hline \multirow[b]{3}{*}{ Country and centre } & \multirow[b]{3}{*}{ Total $n$} & \multicolumn{3}{|c|}{$\begin{array}{l}\text { Sweet buns, cakes \& pies } \\
\left(\mathrm{g} \mathrm{day}^{-1}\right)\end{array}$} & \multicolumn{3}{|c|}{ Sweet biscuits (g day $\left.{ }^{-1}\right)$} \\
\hline & & \multirow[b]{2}{*}{ Crude mean } & \multicolumn{2}{|c|}{ Adjusted $^{*}$} & \multirow[b]{2}{*}{ Crude mean } & \multicolumn{2}{|c|}{ Adjusted $^{*}$} \\
\hline & & & Mean & SEM & & Mean & SEM \\
\hline \multicolumn{8}{|l|}{ Greeces } \\
\hline Greece & 1312 & 14.5 & 15.4 & 2.3 & 7.4 & 6.7 & 0.6 \\
\hline \multicolumn{8}{|l|}{ Spain } \\
\hline Granada & 214 & 21.3 & 25.8 & 5.7 & 7.6 & 6.5 & 1.4 \\
\hline Murcia & 243 & 43.1 & 41.6 & 5.4 & 11.0 & 11.3 & 1.3 \\
\hline Navarra & 444 & 19.2 & 19.3 & 4.0 & 10.8 & 10.5 & 0.9 \\
\hline San Sebastian & 490 & 24.6 & 24.2 & 3.8 & 9.7 & 9.9 & 0.9 \\
\hline Asturias & 386 & 27.3 & 27.7 & 4.3 & 9.6 & 9.4 & 1.0 \\
\hline \multicolumn{8}{|l|}{ Italy } \\
\hline Ragusa & 168 & 30.1 & 37.8 & 6.5 & 16.3 & 12.0 & 1.5 \\
\hline Florence & 271 & 47.7 & 47.4 & 5.1 & 13.1 & 13.4 & 1.2 \\
\hline Turin & 677 & 33.8 & 35.5 & 3.2 & 13.4 & 13.5 & 0.8 \\
\hline Varese & 328 & 40.6 & 36.9 & 4.6 & 19.6 & 21.4 & 1.1 \\
\hline \multicolumn{8}{|l|}{ Germany } \\
\hline Heidelberg & 1033 & 53.1 & 63.2 & 2.6 & 4.2 & 4.6 & 0.6 \\
\hline Potsdam & 1235 & 50.3 & 57.4 & 2.4 & 5.1 & 5.6 & 0.6 \\
\hline \multicolumn{8}{|l|}{ The Netherlands } \\
\hline Bilthoven & 1024 & 36.6 & 36.5 & 2.7 & 11.1 & 11.1 & 0.6 \\
\hline \multicolumn{8}{|l|}{ United Kingdom } \\
\hline General population & 404 & 69.7 & 69.0 & 4.2 & 12.7 & 12.6 & 1.0 \\
\hline ‘Health-conscious' & 114 & 59.3 & 59.2 & 7.8 & 10.6 & 10.2 & 1.7 \\
\hline \multicolumn{8}{|l|}{ Denmark } \\
\hline Copenhagen & 1356 & 33.8 & 36.7 & 2.3 & 5.8 & 6.3 & 0.5 \\
\hline Aarhus & 567 & 44.2 & 46.8 & 3.5 & 9.0 & 8.4 & 0.8 \\
\hline \multicolumn{8}{|l|}{ Sweden } \\
\hline Malmö & 1421 & 51.8 & 54.1 & 2.3 & 5.9 & 5.6 & 0.6 \\
\hline Umeå & 1344 & 69.0 & 69.8 & 2.3 & 5.6 & 5.8 & 0.5 \\
\hline
\end{tabular}

SEM - standard error of the mean.

${ }^{*}$ Adjusted for age and standardised for day of the week and season.

order to standardise habitual dietary intakes reported across the EPIC study centres, a calibration study using 24hour dietary recall interviews among sub-samples of each study population was implemented. Individuals of the calibration population were randomly selected from each national cohort in proportion to the expected number of cumulative cancer cases by gender and 5-year age strata, and completed a single 24-hour dietary recall interview $(n=36900)$. The final calibration samples represent $5-$ $12 \%$ of the population of each study centre. Over all EPIC centres, a total of 22924 women and 13031 men were considered in the analysis, after exclusion of subjects under the age of 35 and over the age of 74 years. The sampling procedure was defined to control for possible day-to-day and seasonal variations in diet. Specific details about the calibration studies in each country and the main characteristics of the calibration populations are described elsewhere in this supplement ${ }^{27}$.

\section{Dietary data}

Details of the computerised 24-hour dietary recall interview software (EPIC-SOFT) developed for the calibration study are given elsewhere ${ }^{28,29}$. During the 24-hour dietary recall interview, the EPIC-SOFT system collected information about all food and beverage items consumed. Common rules for describing, quantifying and checking the 1500-2200 foods and 150-350 mixed recipes per country were pre-entered into the system. The 24-hour diet recalls were collected by a total of 90 interviewers. Almost all centres used face-to-face interviews, except in Norway where telephone interviews were used. During the calibration study, preliminary and country-specific national food composition tables were used together with the EPIC-SOFT system to calculate crude intakes of total energy and macronutrients. These estimates were used for quality control purposes and in this paper for the preliminary descriptive and methodological analyses.

A total of 33 food groups were initially identified as potential major contributors of carbohydrates in the EPIC countries (see Table 1). The relative carbohydrate contribution and the number of recalls reporting zero consumption of these food groups were examined in a preliminary project across study centres and countries. However, since current European food composition tables compute carbohydrates differently and a common European food composition table is not available ${ }^{30}$, the relative contribution of specific food groups was not examined in the final project. The number of food groups was reduced to 16 , because some (e.g. dessert sauce, 
Table 2c Mean consumption of breakfast cereal, pasta and rice, and salty snacks by men $(n=13031)$ in 19 European Prospective Investigation into Cancer and Nutrition (EPIC) centres

\begin{tabular}{|c|c|c|c|c|c|c|c|c|c|c|}
\hline \multirow[b]{3}{*}{ Country and centre } & \multirow[b]{3}{*}{ Total $n$} & \multicolumn{3}{|c|}{ Breakfast cereal $\left(\mathrm{g} \mathrm{day}^{-1}\right)$} & \multicolumn{3}{|c|}{ Pasta \& rice $\left(\mathrm{g} \mathrm{day}^{-1}\right)$} & \multicolumn{3}{|c|}{ Salty snacks $\left(\mathrm{g} \mathrm{day}^{-1}\right)$} \\
\hline & & \multirow[b]{2}{*}{ Crude mean } & \multicolumn{2}{|c|}{ Adjusted ${ }^{*}$} & \multirow[b]{2}{*}{ Crude mean } & \multicolumn{2}{|c|}{ Adjusted $^{*}$} & \multirow[b]{2}{*}{ Crude mean } & \multicolumn{2}{|c|}{ Adjusted ${ }^{*}$} \\
\hline & & & Mean & SEM & & Mean & SEM & & Mean & SEM \\
\hline \multicolumn{11}{|l|}{ Greece } \\
\hline Greece & 1312 & 1.1 & 0.5 & 1.3 & 72.1 & 81.3 & 3.0 & 0.9 & 2.0 & 0.6 \\
\hline \multicolumn{11}{|l|}{ Spain } \\
\hline Granada & 214 & 0.1 & -0.3 & 3.2 & 54.0 & 63.1 & 7.4 & 2.1 & 1.9 & 1.5 \\
\hline Murcia & 243 & 0.7 & 1.0 & 3.0 & 58.2 & 53.3 & 7.0 & 1.3 & 1.1 & 1.4 \\
\hline Navarra & 444 & 0.3 & 0.3 & 2.2 & 30.4 & 30.3 & 5.2 & 0.3 & 0.2 & 1.0 \\
\hline San Sebastian & 490 & 0.8 & 1.8 & 2.1 & 36.8 & 29.5 & 5.0 & 0.4 & 0 & 1.0 \\
\hline Asturias & 386 & 1.4 & 1.7 & 2.4 & 47.5 & 47.9 & 5.5 & 0.5 & 0.5 & 1.1 \\
\hline \multicolumn{11}{|l|}{ Italy } \\
\hline Ragusa & 168 & 1.3 & 1.5 & 3.6 & 222.1 & 228.7 & 8.4 & 13.3 & 8.9 & 1.7 \\
\hline Florence & 271 & 2.2 & 2.6 & 2.8 & 239.2 & 234.4 & 6.6 & 15.7 & 16.5 & 1.3 \\
\hline Turin & 677 & 0.8 & 1.3 & 1.8 & 202.4 & 202.2 & 4.2 & 8.4 & 8.4 & 0.8 \\
\hline Varese & 328 & 1.2 & 0.5 & 2.6 & 266.8 & 268.3 & 6.0 & 4.7 & 6.0 & 1.2 \\
\hline \multicolumn{11}{|l|}{ Germany } \\
\hline Heidelberg & 1033 & 6.4 & 6.5 & 1.5 & 73.2 & 68.5 & 3.4 & 5.2 & 4.9 & 0.7 \\
\hline Potsdam & 1235 & 3.2 & 3.0 & 1.3 & 23.5 & 22.1 & 3.1 & 2.7 & 2.5 & 0.6 \\
\hline \multicolumn{11}{|l|}{ The Netherlands } \\
\hline Bilthoven & 1024 & 3.3 & 4.6 & 1.5 & 53.2 & 43.9 & 3.5 & 12.5 & 11.4 & 0.7 \\
\hline \multicolumn{11}{|l|}{ United Kingdom } \\
\hline General population & 404 & 34.8 & 33.3 & 2.3 & 29.8 & 32.1 & 5.4 & 15.0 & 15.4 & 1.1 \\
\hline 'Health-conscious' & 114 & 61.1 & 62.5 & 4.4 & 59.1 & 44.3 & 10.2 & 8.1 & 12.0 & 2.0 \\
\hline \multicolumn{11}{|l|}{ Denmark } \\
\hline Copenhagen & 1356 & 23.0 & 21.3 & 1.3 & 38.1 & 36.8 & 3.0 & 3.2 & 3.1 & 0.6 \\
\hline Aarhus & 567 & 24.6 & 22.4 & 2.0 & 32.0 & 30.5 & 4.6 & 3.9 & 3.1 & 0.9 \\
\hline \multicolumn{11}{|l|}{ Sweden } \\
\hline Malmö & 1421 & 29.9 & 28.0 & 1.3 & 27.8 & 36.4 & 3.0 & 2.5 & 3.9 & 0.6 \\
\hline Umeå & 1344 & 50.6 & 50.0 & 1.3 & 41.7 & 42.0 & 3.0 & 3.7 & 4.0 & 0.6 \\
\hline
\end{tabular}

SEM - standard error of the mean.

* Adjusted for age and standardised for day of the week and season.

pastry) had a very low frequency of consumption (less than $10 \%$ of recalls contained items from the food group) and others (e.g. sauce, flour, meat and fish products, nonalcoholic beverages) contributed less than $1 \%$ to total carbohydrate intake in most centres. Foods contributing small amounts of carbohydrates were either combined into broader food groups (e.g. vegetables and legumes, milk and milk products) or excluded from further examination (e.g. meat and fish products). The current paper examines the following food groups: bread; crispbread; pasta and rice; breakfast cereal; sweet buns, cakes and pies; sweet biscuits; salty biscuits and snacks; potato; vegetables and legumes; fruits; fruit and vegetable juices; sugar and jam; sweets; chocolates; soft drinks; and milk and milk products.

\section{Analysis}

Analysis was conducted separately for men and women. The SPSS statistical package was used for all statistical procedures $^{31}$. The percentage of 24-hour dietary recalls reporting consumption of a food group and the crude mean food group intakes are described for each EPIC centre. Preliminary analysis indicated that the distribution of participants across seasons and days of the week was not equal across study centres. Therefore a standardisation procedure to control for day-to-day and seasonal differences across centres was used in the multivariate analysis. Thus the age-adjusted mean food group intakes were computed for each EPIC centre with centre-specific weights for season and day of the week, using the General Linear Model. The computation of adjusted mean intakes was also repeated including total energy in the model, using the crude macronutrient data of EPIC-SOFT.

\section{Results}

As reported in Table 1, the 10 food groups contributing the most carbohydrates in the EPIC population were: bread (27\% of total carbohydrate intake); fruit (13\%); milk and milk products (8\%); sweet buns, cakes and pies (7\%); potato (7\%); sugar and jam (6\%); pasta and rice (6\%); vegetables and legumes (4\%); crispbread (3\%); and fruit and vegetable juices (3\%). Table 1 also suggests that men overall have higher absolute intakes of vegetables and legumes, bread, soft drinks, potatoes, pasta and rice, breakfast cereal, and sugar and jam than women. Data shown are not adjusted for energy, because only crude energy data were available.

The percentage of 24-hour dietary recalls that include a particular food group depends both on the proportion of regular consumers in the population and on how often these individuals select a food item from the food group. 
Table 2d Mean consumption of potatoes, vegetables and legumes, and fruits by men $(n=13031)$ in 19 European Prospective Investigation into Cancer and Nutrition (EPIC) centres

\begin{tabular}{|c|c|c|c|c|c|c|c|c|c|c|}
\hline \multirow[b]{3}{*}{ Country and centre } & \multirow[b]{3}{*}{ Total $n$} & \multicolumn{3}{|c|}{ Potatoes $\left(\mathrm{g} \mathrm{day}^{-1}\right)$} & \multicolumn{3}{|c|}{$\begin{array}{l}\text { Vegetables \& legumes } \\
\qquad\left(\text { g day }^{-1}\right)\end{array}$} & \multicolumn{3}{|c|}{ Fruits (g day ${ }^{-1}$ ) } \\
\hline & & \multirow[b]{2}{*}{ Crude mean } & \multicolumn{2}{|c|}{ Adjusted ${ }^{*}$} & \multirow[b]{2}{*}{ Crude mean } & \multicolumn{2}{|c|}{ Adjusted ${ }^{*}$} & \multirow[b]{2}{*}{ Crude mean } & \multicolumn{2}{|c|}{ Adjusted ${ }^{*}$} \\
\hline & & & Mean & SEM & & Mean & SEM & & Mean & SEM \\
\hline \multicolumn{11}{|l|}{ Greece } \\
\hline Greece & 1312 & 46.3 & 43.1 & 3.5 & 299.0 & 302.2 & 4.5 & 236.2 & 272.1 & 6.6 \\
\hline \multicolumn{11}{|l|}{ Spain } \\
\hline Granada & 214 & 81.1 & 79.2 & 8.5 & 269.7 & 254.6 & 11.0 & 382.4 & 353.0 & 16.3 \\
\hline Murcia & 243 & 84.6 & 85.1 & 8.0 & 301.0 & 306.4 & 10.3 & 438.2 & 453.8 & 15.3 \\
\hline Navarra & 444 & 69.9 & 70.4 & 5.9 & 296.5 & 292.5 & 7.6 & 315.2 & 312.5 & 11.3 \\
\hline San Sebastian & 490 & 86.5 & 89.5 & 5.7 & 290.7 & 291.4 & 7.3 & 369.4 & 381.5 & 10.9 \\
\hline Asturias & 386 & 99.1 & 98.5 & 6.3 & 210.2 & 213.0 & 8.2 & 337.3 & 339.8 & 12.1 \\
\hline \multicolumn{11}{|l|}{ Italy } \\
\hline Ragusa & 168 & 59.0 & 57.5 & 9.6 & 189.1 & 187.2 & 12.4 & 391.3 & 438.6 & 18.4 \\
\hline Florence & 271 & 50.8 & 50.6 & 7.5 & 229.3 & 234.9 & 9.8 & 373.8 & 404.0 & 14.5 \\
\hline Turin & 677 & 49.6 & 51.9 & 4.8 & 261.6 & 255.1 & 6.2 & 410.4 & 418.5 & 9.2 \\
\hline Varese & 328 & 49.7 & 45.1 & 6.9 & 188.0 & 215.5 & 8.9 & 343.4 & 345.9 & 13.2 \\
\hline \multicolumn{11}{|l|}{ Germany } \\
\hline Heidelberg & 1033 & 79.6 & 87.9 & 3.9 & 177.2 & 175.9 & 5.0 & 173.2 & 166.6 & 7.5 \\
\hline Potsdam & 1235 & 109.5 & 114.9 & 3.5 & 151.9 & 157.9 & 4.6 & 236.8 & 239.0 & 6.8 \\
\hline \multicolumn{11}{|l|}{ The Netherlands } \\
\hline Bilthoven & 1024 & 120.9 & 127.4 & 4.0 & 141.4 & 142.1 & 5.2 & 155.8 & 166.4 & 7.7 \\
\hline \multicolumn{11}{|l|}{ United Kingdom } \\
\hline General population & 404 & 111.2 & 110.7 & 6.2 & 166.6 & 169.1 & 8.0 & 148.7 & 152.2 & 11.9 \\
\hline 'Health-conscious’ & 114 & 92.9 & 105.5 & 11.6 & 248.2 & 255.5 & 15.1 & 261.0 & 255.0 & 22.3 \\
\hline \multicolumn{11}{|l|}{ Denmark } \\
\hline Copenhagen & 1356 & 100.7 & 105.3 & 3.4 & 142.3 & 150.5 & 4.4 & 140.6 & 143.2 & 6.5 \\
\hline Aarhus & 567 & 115.5 & 117.0 & 5.2 & 131.4 & 135.8 & 6.8 & 180.4 & 178.2 & 10.0 \\
\hline \multicolumn{11}{|l|}{ Sweden } \\
\hline Malmö & 1421 & 131.7 & 128.2 & 3.5 & 125.2 & 127.6 & 4.5 & 135.3 & 120.8 & 6.7 \\
\hline Umeå & 1344 & 147.6 & 148.7 & 3.4 & 106.7 & 105.4 & 4.4 & 124.9 & 120.7 & 6.5 \\
\hline
\end{tabular}

SEM - standard error of the mean.

*Adjusted for age and standardised for day of the week and season.

The percentage of recalls that included bread, vegetables and legumes, fruit, and sugar and jam was high in all centres. The percentage of 24-hour dietary recalls including bread ranged from $91 \%$ to $98 \%$ in men and from $83 \%$ to $94 \%$ in women. In Umeå (Sweden), however, only $79 \%$ of recalls (both genders) included bread. Vegetables and legumes were found in at least $81 \%$ of recalls in men and in $84 \%$ in women. Fruit was included more commonly in recalls of women ( $72 \%)$, compared with men (58\%). The corresponding numbers for sugar and jam were 59\% in men and 52\% in women and for milk products, $52 \%$ and $62 \%$, respectively.

The percentage of recalls including pasta and rice was low in most centres, but high in Italian centres, where the range was from $69 \%$ to $80 \%$ in women, and from $79 \%$ to $90 \%$ in men. The number of recalls including potatoes was lowest in Italian and Greek centres (less than 38\%) and similar for men and women. In French centres (women only) the percentage of recalls that included potato varied from $28 \%$ to $44 \%$. In other centres, the percentage ranged from $41 \%$ to $73 \%$ (both men and women). Although few recalls in most centres included sweet biscuits, sweet buns, cakes and pies, crispbread, breakfast cereal and juice, there were some distinct exceptions. Among women in Utrecht (The Netherlands), 56\% of recalls included sweet biscuit consumption. Also, the percentage of recalls including sweet buns, cakes and pies was high in the Swedish centres (Umeå, 59\% in men, 58\% in women; Malmö, 49\% in men, 56\% in women) and in women in Utrecht, The Netherlands (50\%). Crispbread consumption appeared particularly common among participants in Umeå (Sweden). Breakfast cereal consumption was most common in the UK and in Umeå (Sweden). The percentage of recalls including fruit and vegetable juices was highest in Murcia, Spain (men, 61\%; women, 60\%), but it was also high in the 'health-conscious' UK population, in Greece, Germany and The Netherlands. Few recalls overall included soft drinks, sweets, chocolates, and salty biscuits and snacks. Soft drinks consumption appeared uncommon among French women (7-9\% of recalls). The highest percentages were seen among men in Bilthoven, The Netherlands (38\%) and among women in the North \& West of Norway (38\%).

\section{Mean intakes}

Crude and age-adjusted (standardised on day of the week and season) mean intakes are displayed in Tables $2 \mathrm{a}-2 \mathrm{f}$ and $3 \mathrm{a}-3 \mathrm{f}$; age-adjusted mean intakes are presented in 
Table 2e Mean consumption of fruit and vegetable juices, soft drinks, and milk and milk products by men ( $n=13031)$ in 19 European Prospective Investigation into Cancer and Nutrition (EPIC) centres

\begin{tabular}{|c|c|c|c|c|c|c|c|c|c|c|}
\hline \multirow[b]{3}{*}{ Country and centre } & \multirow[b]{3}{*}{ Total $n$} & \multicolumn{3}{|c|}{$\begin{array}{l}\text { Fruit \& vegetable } \\
\text { juices }\left(\mathrm{g} \mathrm{day}^{-1}\right)\end{array}$} & \multicolumn{3}{|c|}{ Soft drinks $\left(\mathrm{g} \mathrm{day}^{-1}\right)$} & \multicolumn{3}{|c|}{ Milk \& milk products $\left(\mathrm{g} \mathrm{day}^{-1}\right)$} \\
\hline & & \multirow[b]{2}{*}{ Crude mean } & \multicolumn{2}{|c|}{ Adjusted* $^{*}$} & \multirow[b]{2}{*}{ Crude mean } & \multicolumn{2}{|c|}{ Adjusted $^{*}$} & \multirow[b]{2}{*}{ Crude mean } & \multicolumn{2}{|c|}{ Adjusted $^{*}$} \\
\hline & & & Mean & SEM & & Mean & SEM & & Mean & SEM \\
\hline \multicolumn{11}{|l|}{ Greece } \\
\hline Greece & 1312 & 31.6 & 34.4 & 4.7 & 45.9 & 47.3 & 7.5 & 134.9 & 129.1 & 7.5 \\
\hline \multicolumn{11}{|l|}{ Spain } \\
\hline Granada & 214 & 46.9 & 50.7 & 11.6 & 106.5 & 98.5 & 18.5 & 355.5 & 352.9 & 18.5 \\
\hline Murcia & 243 & 43.0 & 42.3 & 10.9 & 99.7 & 101.1 & 17.4 & 230.3 & 228.6 & 17.4 \\
\hline Navarra & 444 & 28.6 & 27.8 & 8.1 & 52.7 & 52.2 & 12.9 & 270.4 & 269.6 & 12.9 \\
\hline San Sebastian & 490 & 23.2 & 17.7 & 7.8 & 46.5 & 33.1 & 12.4 & 314.9 & 314.4 & 12.4 \\
\hline Asturias & 386 & 38.5 & 35.6 & 8.7 & 77.3 & 80.5 & 13.8 & 394.9 & 391.1 & 13.8 \\
\hline \multicolumn{11}{|l|}{ Italy } \\
\hline Ragusa & 168 & 11.9 & 6.9 & 13.1 & 59.3 & 31.7 & 21.0 & 117.6 & 107.2 & 20.9 \\
\hline Florence & 271 & 22.7 & 20.3 & 10.3 & 29.3 & 25.0 & 16.5 & 170.8 & 168.9 & 16.5 \\
\hline Turin & 677 & 24.6 & 23.2 & 6.6 & 38.7 & 34.3 & 10.4 & 142.7 & 140.2 & 10.4 \\
\hline Varese & 328 & 23.3 & 22.2 & 9.4 & 43.9 & 48.7 & 15.0 & 199.9 & 223.8 & 15.0 \\
\hline \multicolumn{11}{|l|}{ Germany } \\
\hline Heidelberg & 1033 & 186.7 & 182.5 & 5.3 & 149.4 & 141.7 & 8.5 & 190.8 & 177.8 & 8.5 \\
\hline Potsdam & 1235 & 145.6 & 140.6 & 4.9 & 79.8 & 81.1 & 7.7 & 188.8 & 188.6 & 7.7 \\
\hline \multicolumn{11}{|l|}{ The Netherlands } \\
\hline Bilthoven & 1024 & 70.3 & 62.0 & 5.5 & 183.8 & 168.8 & 8.8 & 324.6 & 318.9 & 8.7 \\
\hline \multicolumn{11}{|l|}{ United Kingdom } \\
\hline General population & 404 & 69.4 & 71.8 & 8.5 & 124.1 & 130.2 & 13.5 & 380.3 & 376.5 & 13.5 \\
\hline 'Health-conscious' & 114 & 111.4 & 123.6 & 15.9 & 97.7 & 107.2 & 25.4 & 180.9 & 195.7 & 25.4 \\
\hline \multicolumn{11}{|l|}{ Denmark } \\
\hline Copenhagen & 1356 & 58.0 & 60.5 & 4.6 & 177.5 & 173.7 & 7.4 & 300.7 & 292.7 & 7.4 \\
\hline Aarhus & 567 & 56.7 & 56.7 & 7.2 & 150.4 & 147.8 & 11.4 & 318.6 & 316.7 & 11.4 \\
\hline \multicolumn{11}{|l|}{ Sweden } \\
\hline Malmö & 1421 & 42.7 & 50.3 & 4.8 & 81.3 & 100.5 & 7.6 & 300.4 & 301.8 & 7.6 \\
\hline Umeå & 1344 & 40.4 & 41.8 & 4.7 & 139.8 & 145.4 & 7.4 & 433.9 & 437.2 & 7.4 \\
\hline
\end{tabular}

SEM - standard error of the mean.

*Adjusted for age and standardised for day of the week and season.

Figs. 1a, 1b and 2a, 2b. Energy adjustment influenced the relative ranking of a few centres, but had virtually no influence on the north-south consumption gradients observed. Therefore energy-adjusted data are not shown. The means were computed for the population as a whole (consumers and non-consumers).

Bread, crispbread, sweet buns, cakes and pies, and sweet biscuits

Bread was a major food in all of the EPIC centres, and specific consumption gradients were difficult to distinguish. In men, the highest consumption was observed in Aarhus, Denmark (195g) and the lowest in Umeå, Sweden (77 g). In women, the highest consumption levels were seen in Denmark (Aarhus, $160 \mathrm{~g}$; Copenhagen, $142 \mathrm{~g}$ ) and Norway $(131 \mathrm{~g})$, and the lowest in Sweden (Umeå, $58 \mathrm{~g})$.

Crispbread consumption was low and even across most centres. Umeå (Sweden) stands out, however, with high consumption levels, both in men $(41 \mathrm{~g})$ and in women $(26 \mathrm{~g})$. The lowest levels were found in Heidelberg, Germany (men, $1.5 \mathrm{~g}$ ) and in Aarhus, Denmark (women, $2.7 \mathrm{~g})$.

Consumption of sweet buns, cakes and pies appeared higher in most northern centres. The highest consumption levels were seen in Umeå, Sweden (men, $79 \mathrm{~g}$; women, $59 \mathrm{~g}$ ). Centres in the south and in The Netherlands and Denmark had lower levels; the lowest was in Greece, both in men (15 g) and women (19g). Sweet biscuit consumption was low overall. Varese, Italy had the highest consumption (men and women, $21 \mathrm{~g}$ ). The lowest levels were seen in Heidelberg, Germany (men, $4.6 \mathrm{~g}$ ) and in South \& East Norway (women, $2.4 \mathrm{~g}$ ).

\section{Breakfast cereal, pasta and rice, and salty biscuits and} snacks

Breakfast cereal consumption varied between centres. In men, the UK 'health-conscious' population had the highest consumption (63 g), but Swedish and Danish centres also had high consumption levels. Similarly, in women consumption was highest in Umeå, Sweden (42g), followed by centres in the UK, Sweden, Denmark and Norway. Other centres had, overall, very low consumption levels, with the lowest being in Spanish centres (less than $1 \mathrm{~g})$.

Italian centres had the highest mean levels of consumption of pasta and rice, with the highest in Varese (men, 268g; women, 151g). Other centres had much 
Table $2 f$ Mean consumption of sugar and jam, sweets, and chocolates by men $(n=13031)$ in 19 European Prospective Investigation into Cancer and Nutrition (EPIC) centres

\begin{tabular}{|c|c|c|c|c|c|c|c|c|c|c|}
\hline \multirow[b]{3}{*}{ Country and centre } & \multirow[b]{3}{*}{ Total $n$} & \multicolumn{3}{|c|}{ Sugar \& jam $\left(\right.$ g day $\left.^{-1}\right)$} & \multicolumn{3}{|c|}{ Sweets $\left(\right.$ g day $\left.^{-1}\right)$} & \multicolumn{3}{|c|}{ Chocolates $\left(\mathrm{g} \mathrm{day}^{-1}\right.$ ) } \\
\hline & & \multirow[b]{2}{*}{ Crude mean } & \multicolumn{2}{|c|}{ Adjusted* } & \multirow[b]{2}{*}{ Crude mean } & \multicolumn{2}{|c|}{ Adjusted* } & \multirow[b]{2}{*}{ Crude mean } & \multicolumn{2}{|c|}{ Adjusted* } \\
\hline & & & Mean & SEM & & Mean & SEM & & Mean & SEM \\
\hline \multicolumn{11}{|l|}{ Greece } \\
\hline Greece & 1312 & 11.3 & 10.9 & 0.8 & 3.2 & 2.8 & 0.6 & 1.3 & 1.5 & 0.5 \\
\hline \multicolumn{11}{|l|}{ Spain } \\
\hline Granada & 214 & 15.3 & 15.2 & 2.1 & 3.3 & 3.4 & 1.5 & 2.0 & 2.1 & 1.3 \\
\hline Murcia & 243 & 15.4 & 15.1 & 1.9 & 2.7 & 2.6 & 1.4 & 2.8 & 2.6 & 1.2 \\
\hline Navarra & 444 & 15.0 & 15.1 & 1.4 & 4.1 & 4.0 & 1.0 & 2.3 & 2.3 & 0.9 \\
\hline San Sebastian & 490 & 18.1 & 18.6 & 1.4 & 5.2 & 4.5 & 1.0 & 2.8 & 2.1 & 0.9 \\
\hline Asturias & 386 & 18.7 & 18.9 & 1.5 & 4.4 & 4.2 & 1.1 & 4.7 & 4.7 & 1.0 \\
\hline \multicolumn{11}{|l|}{ Italy } \\
\hline Ragusa & 168 & 17.3 & 16.9 & 2.3 & 0.3 & 0.0 & 1.7 & 1.1 & 0.4 & 1.4 \\
\hline Florence & 271 & 14.1 & 13.8 & 1.8 & 1.5 & 1.4 & 1.3 & 2.6 & 2.5 & 1.1 \\
\hline Turin & 677 & 18.0 & 17.9 & 1.2 & 2.6 & 2.5 & 0.8 & 3.0 & 2.8 & 0.7 \\
\hline Varese & 328 & 24.0 & 25.7 & 1.7 & 4.6 & 3.2 & 1.2 & 3.4 & 3.2 & 1.0 \\
\hline \multicolumn{11}{|l|}{ Germany } \\
\hline Heidelberg & 1033 & 19.8 & 20.0 & 1.0 & 3.1 & 2.3 & 0.7 & 7.3 & 7.3 & 0.6 \\
\hline Potsdam & 1235 & 19.5 & 19.9 & 0.9 & 2.0 & 1.7 & 0.6 & 7.1 & 7.3 & 0.5 \\
\hline \multicolumn{11}{|l|}{ The Netherlands } \\
\hline Bilthoven & 1024 & 31.8 & 32.9 & 1.0 & 8.9 & 8.4 & 0.7 & 8.3 & 7.6 & 0.6 \\
\hline \multicolumn{11}{|l|}{ United Kingdom } \\
\hline General population & 404 & 28.2 & 28.0 & 1.5 & 2.4 & 2.6 & 1.1 & 11.3 & 12.0 & 0.9 \\
\hline 'Health-conscious' & 114 & 18.2 & 16.8 & 2.8 & 2.6 & 1.7 & 2.0 & 3.8 & 3.2 & 1.8 \\
\hline \multicolumn{11}{|l|}{ Denmark } \\
\hline Copenhagen & 1356 & 25.8 & 26.2 & 0.8 & 3.9 & 4.0 & 0.6 & 7.3 & 7.6 & 0.5 \\
\hline Aarhus & 567 & 23.5 & 23.2 & 1.3 & 5.3 & 5.0 & 0.9 & 8.1 & 7.4 & 0.8 \\
\hline \multicolumn{11}{|l|}{ Sweden } \\
\hline Malmö & 1421 & 27.7 & 26.0 & 0.9 & 6.8 & 7.8 & 0.6 & 6.8 & 7.8 & 0.5 \\
\hline Umeå & 1344 & 35.3 & 35.4 & 0.8 & 5.2 & 5.6 & 0.5 & 6.0 & 6.5 & 0.5 \\
\hline
\end{tabular}

SEM - standard error of the mean.

${ }^{*}$ Adjusted for age and standardised for day of the week and season.

lower levels; the lowest in women was in North \& West Norway (15 g) and in men in Potsdam, Germany (22 g).

Consumption of salty snacks was low overall. The highest levels were seen in Italy (men, $17 \mathrm{~g}$ in Florence; women, $16 \mathrm{~g}$ in Naples) and the UK 'general population' (men, $15 \mathrm{~g}$; women, $12 \mathrm{~g}$ ). Spanish centres had the lowest levels, $1 \mathrm{~g}$ or less for both genders.

\section{Potato, and vegetables and legumes}

Potato consumption also varied between EPIC centres. Umeå, Sweden had the highest consumption (men, $149 \mathrm{~g}$; women, $92 \mathrm{~g}$ ), followed by other centres in northern Europe. Consumption was lowest in Ragusa, Italy (women, $26 \mathrm{~g}$; men, $43 \mathrm{~g}$ ). The amounts of vegetables and legumes eaten varied across EPIC centres. In men, vegetable and legume consumption was highest in Murcia, Spain (306g), followed by centres in Greece, the 'healthconscious' group in the UK and Italy, while Umeå, Sweden (105 g) had the lowest mean consumption. In women, vegetable consumption was highest among women in France (South coast, $275 \mathrm{~g}$ ), followed by centres in Spain and Greece, the 'health-conscious' group in the UK and most Italian centres. Consumption was lowest in North \& West Norway (120 g). Clear north-south gradients were observed in both men and women for potatoes and also for vegetables and legumes, although less pronounced.
Fruits, and fruit and vegetable juices

Fruits were commonly consumed in all EPIC centres, but the amounts varied considerably. High levels of consumption were seen in the Italian and Spanish centres, with the highest in Murcia, Spain (men, 454g) and in Ragusa, Italy (women, 397 g). Consumption was moderately high in the 'health-conscious' group in the UK, Greece, Germany and Aarhus (Denmark) and lowest in Sweden (men, $121 \mathrm{~g}$; women, $151 \mathrm{~g}$ ). Fruit and vegetable juice consumption was highest in Heidelberg, Germany (men, $183 \mathrm{~g}$; women, $165 \mathrm{~g}$ ), followed by The Netherlands, the UK and Norway (women). Ragusa, Italy had the lowest mean consumption (men, $6.9 \mathrm{~g}$; women, $4.4 \mathrm{~g}$ ). Thus fruit as well as fruit and vegetable juices clearly show opposing north-south gradients.

Soft drinks, sugar and jam, sweets, and chocolates

Soft drinks consumption varied considerably across EPIC centres with clear north-south gradients. In men, Copenhagen (Denmark) had the highest mean consumption of soft drinks ( $174 \mathrm{~g}$ ) and Florence (Italy) had the lowest consumption (25g). In women, South \& East (163 g) and North \& West (159 g) Norway had the highest mean consumption levels of soft drinks, while the South coast of France (12 g) had the lowest.

The consumption of sugar and jam, sweets, and 
Table 3a Mean consumption of bread and crispbread by women $(n=22924)$ in 27 European Prospective Investigation into Cancer and Nutrition (EPIC) centres

\begin{tabular}{|c|c|c|c|c|c|c|c|}
\hline \multirow[b]{3}{*}{ Country and centre } & \multirow[b]{3}{*}{ Total $n$} & \multicolumn{3}{|c|}{ Bread $\left(\right.$ g day $\left.^{-1}\right)$} & \multicolumn{3}{|c|}{ Crispbread $\left(\mathrm{g} \mathrm{day}^{-1}\right)$} \\
\hline & & \multirow[b]{2}{*}{ Crude mean } & \multicolumn{2}{|c|}{ Adjusted* } & \multirow[b]{2}{*}{ Crude mean } & \multicolumn{2}{|c|}{ Adjusted ${ }^{*}$} \\
\hline & & & Mean & SEM & & Mean & SEM \\
\hline \multicolumn{8}{|l|}{ Greece } \\
\hline Greece & 1374 & 109.6 & 102.6 & 2.1 & 10.9 & 11.5 & 0.4 \\
\hline \multicolumn{8}{|l|}{ Spain } \\
\hline Granada & 300 & 90.9 & 96.7 & 4.4 & 3.9 & 4.9 & 0.9 \\
\hline Murcia & 304 & 76.3 & 76.2 & 4.4 & 6.2 & 6.7 & 0.9 \\
\hline Navarra & 271 & 88.8 & 88.4 & 4.7 & 6.9 & 6.9 & 1.0 \\
\hline San Sebastian & 244 & 80.8 & 79.6 & 4.9 & 8.9 & 9.8 & 1.0 \\
\hline Asturias & 324 & 74.2 & 74.2 & 4.3 & 10.4 & 10.2 & 0.9 \\
\hline \multicolumn{8}{|l|}{ Italy } \\
\hline Ragusa & 138 & 102.5 & 93.4 & 6.5 & 6.3 & 5.8 & 1.3 \\
\hline Naples & 403 & 103.6 & 97.1 & 3.8 & 7.6 & 8.1 & 0.8 \\
\hline Florence & 785 & 97.6 & 97.8 & 2.7 & 7.9 & 8.0 & 0.6 \\
\hline Turin & 392 & 84.0 & 85.3 & 3.9 & 17.1 & 16.6 & 0.8 \\
\hline Varese & 794 & 75.9 & 77.6 & 2.7 & 7.5 & 7.3 & 0.6 \\
\hline \multicolumn{8}{|l|}{ France } \\
\hline South coast & 612 & 85.0 & 92.9 & 3.1 & 8.1 & 7.4 & 0.6 \\
\hline South & 1396 & 100.8 & 100.7 & 2.1 & 7.8 & 7.3 & 0.4 \\
\hline North-west & 622 & 96.7 & 99.3 & 3.1 & 3.9 & 3.2 & 0.6 \\
\hline North-east & 2009 & 92.7 & 94.5 & 1.7 & 5.1 & 4.8 & 0.4 \\
\hline \multicolumn{8}{|l|}{ Germany } \\
\hline Heidelberg & 1087 & 101.1 & 102.5 & 2.4 & 2.8 & 2.9 & 0.5 \\
\hline Potsdam & 1063 & 106.4 & 104.7 & 2.4 & 3.8 & 4.4 & 0.5 \\
\hline \multicolumn{8}{|l|}{ The Netherlands } \\
\hline Bilthoven & 1086 & 116.5 & 114.8 & 2.4 & 4.2 & 4.8 & 0.5 \\
\hline Utrecht & 1874 & 110.1 & 111.0 & 1.8 & 6.3 & 6.0 & 0.4 \\
\hline \multicolumn{8}{|l|}{ United Kingdom } \\
\hline General population & 571 & 83.2 & 83.9 & 3.2 & 3.2 & 3.2 & 0.7 \\
\hline 'Health-conscious' & 197 & 93.2 & 99.8 & 5.5 & 6.2 & 6.5 & 1.1 \\
\hline \multicolumn{8}{|l|}{ Denmark } \\
\hline Copenhagen & 1485 & 140.1 & 141.9 & 2.0 & 3.4 & 3.1 & 0.4 \\
\hline Aarhus & 510 & 154.3 & 159.7 & 3.4 & 3.1 & 2.7 & 0.7 \\
\hline \multicolumn{8}{|l|}{ Sweden } \\
\hline Malmö & 1711 & 69.4 & 71.1 & 1.9 & 9.4 & 8.9 & 0.4 \\
\hline Umeå & 1574 & 57.3 & 57.6 & 1.9 & 25.6 & 25.5 & 0.4 \\
\hline \multicolumn{8}{|l|}{ Norway } \\
\hline South \& East & 1136 & 135.7 & 131.4 & 2.3 & 7.4 & 7.8 & 0.5 \\
\hline North \& West & 662 & 133.1 & 131.0 & 3.0 & 7.8 & 7.9 & 0.6 \\
\hline
\end{tabular}

SEM - standard error of the mean.

${ }^{*}$ Adjusted for age and standardised for day of the week and season.

chocolates was low overall and specific trends were difficult to discern. Sugar and jam consumption was highest among men in Umeå, Sweden $(35 \mathrm{~g})$ and in Bilthoven, The Netherlands (33g) and among women in North \& West Norway (22 g) and Umeå, Sweden (21 g). Consumption was lowest in Greece (men, $11 \mathrm{~g}$ ) and in Florence, Italy (women, $10 \mathrm{~g}$ ). The consumption of sweets ranked high in The Netherlands, Denmark and Sweden, and lowest in Ragusa in Italy. Chocolate consumption was highest in the UK general population, but overall higher in northern centres. Men in Ragusa (Italy) and women in Granada (Spain) had the lowest mean consumption of chocolates.

\section{Milk and milk products}

The consumption of milk and milk products varied substantially across EPIC centres. In men, Umeå, Sweden ( $437 \mathrm{~g}$ ) had the highest mean consumption of milk and milk products, followed by the UK general population, Spanish centres, Bilthoven (The Netherlands), Malmö (Sweden) and Danish centres. In women, consumption was highest in Asturias, Spain (462 g), followed by other Spanish centres, Utrecht (The Netherlands), Umeå (Sweden) and the UK general population. The lowest levels were seen both for men (107 g) and women (116 g) in Ragusa (Italy).

\section{Discussion}

This study indicates that several major sources of carbohydrates differ between northern and southern EPIC centres. Fruit consumption is high in most southern centres. A similar pattern, although less pronounced, is observed for vegetables and legumes, with a higher consumption of these foods in southern Europe. Soft drinks consumption is higher in the north, and fruit and 
Table 3b Mean consumption of sweet buns, cakes and pies, and sweet biscuits by women $(n=22924)$ in 27 European Prospective Investigation into Cancer and Nutrition (EPIC) centres

\begin{tabular}{|c|c|c|c|c|c|c|c|}
\hline \multirow[b]{3}{*}{ Country and centre } & \multirow[b]{3}{*}{ Total $n$} & \multicolumn{3}{|c|}{$\begin{array}{l}\text { Sweet buns, cakes \& pies } \\
\left(\mathrm{g} \mathrm{day}^{-1}\right)\end{array}$} & \multicolumn{3}{|c|}{ Sweet biscuits (g day ${ }^{-1}$ ) } \\
\hline & & \multirow[b]{2}{*}{ Crude mean } & \multicolumn{2}{|c|}{ Adjusted ${ }^{*}$} & \multirow[b]{2}{*}{ Crude mean } & \multicolumn{2}{|c|}{ Adjusted ${ }^{*}$} \\
\hline & & & Mean & SEM & & Mean & SEM \\
\hline \multicolumn{8}{|l|}{ Greece } \\
\hline Greece & 1374 & 17.8 & 19.2 & 1.9 & 11.0 & 10.5 & 0.5 \\
\hline \multicolumn{8}{|l|}{ Spain } \\
\hline Granada & 300 & 19.4 & 21.9 & 4.1 & 6.2 & 5.7 & 1.1 \\
\hline Murcia & 304 & 43.7 & 43.0 & 4.1 & 9.9 & 9.9 & 1.1 \\
\hline Navarra & 271 & 29.6 & 30.4 & 4.4 & 14.0 & 14.3 & 1.2 \\
\hline San Sebastian & 244 & 26.3 & 28.7 & 4.6 & 10.4 & 9.4 & 1.2 \\
\hline Asturias & 324 & 28.4 & 30.2 & 4.0 & 10.7 & 11.0 & 1.1 \\
\hline \multicolumn{8}{|l|}{ Italy } \\
\hline Ragusa & 138 & 35.3 & 38.1 & 6.1 & 16.4 & 13.9 & 1.7 \\
\hline Naples & 403 & 39.6 & 37.4 & 3.6 & 9.9 & 9.6 & 1.0 \\
\hline Florence & 785 & 38.0 & 37.9 & 2.6 & 12.3 & 12.2 & 0.7 \\
\hline Turin & 392 & 29.8 & 29.9 & 3.6 & 13.7 & 14.4 & 1.0 \\
\hline Varese & 794 & 31.6 & 34.7 & 2.5 & 19.8 & 20.6 & 0.7 \\
\hline \multicolumn{8}{|l|}{ France } \\
\hline South coast & 612 & 35.6 & 36.9 & 2.9 & 5.9 & 6.5 & 0.8 \\
\hline South & 1396 & 39.6 & 41.3 & 1.9 & 6.3 & 6.2 & 0.5 \\
\hline North-west & 622 & 44.7 & 45.1 & 2.9 & 4.2 & 4.2 & 0.8 \\
\hline North-east & 2009 & 47.3 & 50.3 & 1.6 & 6.5 & 6.4 & 0.4 \\
\hline \multicolumn{8}{|l|}{ Germany } \\
\hline Heidelberg & 1087 & 45.5 & 51.9 & 2.2 & 7.4 & 7.7 & 0.6 \\
\hline Potsdam & 1063 & 48.9 & 50.9 & 2.2 & 4.6 & 4.9 & 0.6 \\
\hline \multicolumn{8}{|l|}{ The Netherlands } \\
\hline Bilthoven & 1086 & 41.1 & 42.2 & 2.2 & 13.0 & 12.9 & 0.6 \\
\hline Utrecht & 1874 & 39.0 & 39.6 & 1.7 & 15.9 & 16.4 & 0.5 \\
\hline \multicolumn{8}{|l|}{ United Kingdom } \\
\hline General population & 571 & 48.4 & 51.0 & 3.0 & 10.5 & 10.4 & 0.8 \\
\hline 'Health-conscious' & 197 & 50.4 & 54.3 & 5.1 & 8.9 & 8.2 & 1.4 \\
\hline \multicolumn{8}{|l|}{ Denmark } \\
\hline Copenhagen & 1485 & 30.5 & 33.1 & 1.7 & 5.67 & 5.8 & 0.5 \\
\hline Aarhus & 510 & 45.6 & 49.2 & 3.2 & 8.67 & 8.2 & 0.9 \\
\hline \multicolumn{8}{|l|}{ Sweden } \\
\hline Malmö & 1711 & 52.5 & 52.6 & 1.8 & 5.4 & 5.4 & 0.5 \\
\hline Umeå & 1574 & 58.3 & 59.1 & 1.8 & 5.3 & 5.6 & 0.5 \\
\hline \multicolumn{8}{|l|}{ Norway } \\
\hline South \& East & 1136 & 48.1 & 49.1 & 2.2 & 2.7 & 2.4 & 0.6 \\
\hline North \& West & 662 & 54.6 & 55.1 & 2.8 & 2.9 & 2.7 & 0.8 \\
\hline
\end{tabular}

SEM - standard error of the mean.

${ }^{*}$ Adjusted for age and standardised for day of the week and season.

vegetable juices higher in north-west and central Europe. Potato consumption is high in northern centres and low in the south of Europe. Breakfast cereals are consumed more in the northern centres and Italian centres have high pasta and rice consumption. Consumption of sweet buns, cakes and pies is higher in northern compared with southern centres, but consumption of sweet biscuits is more evenly distributed. The consumption of bread and crispbread shows an opposing gradient to that of sweet buns, cakes and pies and sweet biscuits, although not so clearly along a north-south axis. In Sweden, lower bread consumption is balanced by a higher consumption of crispbread. Consumption of milk and milk products is higher in most northern centres and in Spain. Thus the consumption levels of fruits, vegetables and legumes, and pasta and rice are not only lower in northern compared with southern centres, but the levels of consumption of potatoes, breakfast cereals (in some centres), soft drinks, sweet buns, cakes and pies, and juice (in some centres) are also higher, and therefore constitute a larger part of the diet. Although there are reports that food practices in the Mediterranean region are incorporating Westernised food styles $^{32,33}$, this study shows that the foods providing carbohydrates are still quite different in southern compared with northern Europe.

Differences between food habits of populations depend on factors such as culture, climate and geography, and agricultural, economic and technical development. The traditional diets of the Mediterranean region were high in vegetables, fruits and pulses, with cereals (wheat) contributing a large part of the energy content. In traditional northern European diets, a smaller proportion of energy came from cereals (rye, oats and barley rather than wheat) and potatoes were commonly eaten. Animal 
Table 3c Mean consumption of breakfast cereal, pasta and rice, and salty snacks by women $(n=22924)$ in 27 European Prospective Investigation into Cancer and Nutrition (EPIC) centres

\begin{tabular}{|c|c|c|c|c|c|c|c|c|c|c|}
\hline \multirow[b]{3}{*}{ Country and centre } & \multirow[b]{3}{*}{ Total $n$} & \multicolumn{3}{|c|}{ Breakfast cereal $\left(\mathrm{g} \mathrm{day}^{-1}\right)$} & \multicolumn{3}{|c|}{ Pasta \& rice $\left(\mathrm{g} \mathrm{day}^{-1}\right)$} & \multicolumn{3}{|c|}{ Salty snacks $\left(\mathrm{g} \mathrm{day}^{-1}\right)$} \\
\hline & & \multirow[b]{2}{*}{ Crude mean } & \multicolumn{2}{|c|}{ Adjusted ${ }^{*}$} & \multirow[b]{2}{*}{ Crude mean } & \multicolumn{2}{|c|}{ Adjusted* } & \multirow[b]{2}{*}{ Crude mean } & \multicolumn{2}{|c|}{ Adjusted $^{*}$} \\
\hline & & & Mean & SEM & & Mean & SEM & & Mean & SEM \\
\hline \multicolumn{11}{|l|}{ Greece } \\
\hline Greece & 1374 & 1.2 & 1.2 & 1.0 & 51.7 & 53.2 & 2.1 & 1.2 & 1.8 & 0.6 \\
\hline \multicolumn{11}{|l|}{ Spain } \\
\hline Granada & 300 & 0.6 & 0.6 & 2.0 & 24.0 & 23.3 & 4.5 & 1.5 & 1.2 & 1.2 \\
\hline Murcia & 304 & 0.4 & 0.8 & 2.0 & 29.7 & 28.9 & 4.5 & 1.3 & 1.2 & 1.2 \\
\hline Navarra & 271 & 0.5 & 0.5 & 2.2 & 27.7 & 26.7 & 4.7 & 0.5 & 0.3 & 1.3 \\
\hline San Sebastian & 244 & 1.7 & 1.9 & 2.3 & 28.9 & 26.7 & 5.0 & 0.5 & 0 & 1.3 \\
\hline Asturias & 324 & 1.3 & 1.3 & 2.0 & 34.3 & 33.5 & 4.3 & 1.4 & 1.1 & 1.1 \\
\hline \multicolumn{11}{|l|}{ Italy } \\
\hline Ragusa & 138 & 0.4 & 0.8 & 3.0 & 125.0 & 101.7 & 6.6 & 3.2 & 2.2 & 1.8 \\
\hline Naples & 403 & 2.0 & 1.5 & 1.8 & 124.7 & 125.1 & 3.9 & 12.1 & 15.5 & 1.0 \\
\hline Florence & 785 & 1.8 & 1.9 & 1.3 & 125.7 & 126.5 & 2.8 & 10.1 & 10.1 & 0.7 \\
\hline Turin & 392 & 1.4 & 1.5 & 1.8 & 110.8 & 110.1 & 3.9 & 6.7 & 6.8 & 1.0 \\
\hline Varese & 794 & 2.6 & 2.5 & 1.3 & 147.1 & 150.5 & 2.8 & 5.6 & 5.2 & 0.7 \\
\hline \multicolumn{11}{|l|}{ France } \\
\hline South coast & 612 & 4.2 & 4.5 & 1.4 & 42.2 & 45.0 & 3.1 & 4.6 & 4.1 & 0.8 \\
\hline South & 1396 & 5.0 & 4.4 & 1.0 & 44.0 & 43.2 & 2.1 & 4.1 & 4.4 & 0.6 \\
\hline North-west & 622 & 4.9 & 4.8 & 1.4 & 36.5 & 37.7 & 3.1 & 5.7 & 5.1 & 0.8 \\
\hline North-east & 2009 & 4.3 & 3.7 & 0.8 & 40.0 & 40.1 & 1.7 & 6.2 & 6.8 & 0.5 \\
\hline \multicolumn{11}{|l|}{ Germany } \\
\hline Heidelberg & 1087 & 4.7 & 5.3 & 1.1 & 55.3 & 49.8 & 2.4 & 4.5 & 3.9 & 0.6 \\
\hline Potsdam & 1063 & 3.4 & 3.6 & 1.1 & 26.7 & 26.5 & 2.4 & 2.9 & 2.3 & 0.6 \\
\hline \multicolumn{11}{|l|}{ The Netherlands } \\
\hline Bilthoven & 1086 & 3.3 & 4.0 & 1.1 & 37.2 & 33.2 & 2.4 & 10.9 & 10.4 & 0.6 \\
\hline Utrecht & 1874 & 3.6 & 3.2 & 0.8 & 24.1 & 25.5 & 1.8 & 8.8 & 9.4 & 0.5 \\
\hline \multicolumn{11}{|l|}{ United Kingdom } \\
\hline General population & 571 & 23.9 & 23.5 & 1.5 & 25.8 & 26.6 & 3.2 & 11.8 & 11.6 & 0.9 \\
\hline 'Health-conscious' & 197 & 30.5 & 29.3 & 2.5 & 50.5 & 43.8 & 5.5 & 8.4 & 7.9 & 1.5 \\
\hline \multicolumn{11}{|l|}{ Denmark } \\
\hline Copenhagen & 1485 & 16.3 & 15.6 & 0.9 & 28.3 & 28.5 & 2.0 & 3.5 & 3.4 & 0.5 \\
\hline Aarhus & 510 & 15.7 & 16.0 & 1.6 & 26.5 & 26.2 & 3.4 & 2.3 & 2.1 & 0.9 \\
\hline \multicolumn{11}{|l|}{ Sweden } \\
\hline Malmö & 1711 & 19.4 & 18.1 & 0.9 & 23.4 & 27.0 & 1.9 & 3.3 & 4.1 & 0.5 \\
\hline Umeå & 1574 & 42.3 & 42.0 & 0.9 & 30.2 & 29.2 & 2.0 & 3.6 & 3.6 & 0.5 \\
\hline \multicolumn{11}{|l|}{ Norway } \\
\hline South \& East & 1136 & 13.1 & 14.9 & 1.1 & 20.1 & 16.5 & 2.3 & 4.5 & 4 & 0.6 \\
\hline North \& West & 662 & 11.5 & 11.9 & 1.4 & 18.2 & 14.6 & 3.0 & 5.0 & 3.8 & 0.8 \\
\hline
\end{tabular}

SEM - standard error of the mean.

${ }^{*}$ Adjusted for age and standardised for day of the week and season.

products provided a larger part of dietary energy and intakes of milk and milk products were high ${ }^{2}$. Traditional Mediterranean diets are generally considered to promote good health ${ }^{34,35}$; this is especially true for cardiovascular health ${ }^{36,37}$, but also for some types of cancer ${ }^{38,39}$. For instance, total mortality from malignant neoplasm was low in Mediterranean countries compared with the UK during the latter part of the last century ${ }^{32}$ and lung cancer rates were low in southern Europe in spite of high rates of cigarette smoking ${ }^{32}$. In addition, the protective effects of vegetables and fruits with regard to a number of cancers $^{2,40}$ and cardiovascular disease ${ }^{41,42}$ have been documented.

European food habits underwent drastic changes during the second half of the last century. Thus the dietary differences across European regions may have diminished substantially $^{32,33}$. Most studies describing these changes either use food balance sheets ${ }^{32}$ or look at trends within single countries ${ }^{43}$. Others compare food habits of a few study centres and countries ${ }^{44}$ or those of studies using dissimilar dietary methodologies ${ }^{45}$. Comparisons on food availability in 14 European countries are also feasible, using data retrieved from the DAFNE databank (the DAta Food NEtworking initiative and DafneSoft program, http://www.nut.uoa.gr), which comprises comparable food and related data collected in national household budget surveys. Few studies have, however, compared dietary intake data collected from individuals in several countries simultaneously. The major advantage of the current project is that it uses dietary data from the EPIC calibration study, with standardised study design and dietary methodology in all centres. Also, it is of great importance for future analytical projects within the EPIC study that major differences in carbohydrate-containing foods could be demonstrated.

This study provided only preliminary information on 
Table 3d Mean consumption of potatoes, vegetables and legumes, and fruits by women $(n=22924)$ in 27 European Prospective Investigation into Cancer and Nutrition (EPIC) centres

\begin{tabular}{|c|c|c|c|c|c|c|c|c|c|c|}
\hline \multirow[b]{3}{*}{ Country and centre } & \multirow[b]{3}{*}{ Total $n$} & \multicolumn{3}{|c|}{ Potatoes $\left(\mathrm{g} \mathrm{day}^{-1}\right.$ ) } & \multicolumn{3}{|c|}{$\begin{array}{l}\text { Vegetables \& legumes } \\
\qquad\left(\mathrm{g} \mathrm{day}^{-1}\right)\end{array}$} & \multicolumn{3}{|c|}{ Fruits (g day ${ }^{-1}$ ) } \\
\hline & & \multirow[b]{2}{*}{ Crude mean } & \multicolumn{2}{|c|}{ Adjusted $^{*}$} & \multirow[b]{2}{*}{ Crude mean } & \multicolumn{2}{|c|}{ Adjusted ${ }^{*}$} & \multirow[b]{2}{*}{ Crude mean } & \multicolumn{2}{|c|}{ Adjusted ${ }^{*}$} \\
\hline & & & Mean & SEM & & Mean & SEM & & Mean & SEM \\
\hline \multicolumn{11}{|l|}{ Greece } \\
\hline Greece & 1374 & 34.0 & 32.4 & 2.4 & 229.7 & 225.5 & 4.0 & 219.6 & 238.8 & 5.7 \\
\hline \multicolumn{11}{|l|}{ Spain } \\
\hline Granada & 300 & 54.0 & 55.0 & 5.2 & 248.6 & 220.3 & 8.6 & 352.4 & 338.4 & 12.1 \\
\hline Murcia & 304 & 67.6 & 68.1 & 5.1 & 272.9 & 268.2 & 8.5 & 372.6 & 379.3 & 12.1 \\
\hline Navarra & 271 & 51.5 & 54.0 & 5.4 & 219.4 & 219.2 & 9.0 & 320.3 & 330.1 & 12.7 \\
\hline San Sebastian & 244 & 60.5 & 64.4 & 5.7 & 257.1 & 250.5 & 9.5 & 370.0 & 365.4 & 13.4 \\
\hline Asturias & 324 & 70.3 & 71.5 & 5.0 & 140.3 & 138.6 & 8.2 & 325.5 & 335.9 & 11.7 \\
\hline \multicolumn{11}{|l|}{ Italy } \\
\hline Ragusa & 138 & 25.4 & 26.2 & 7.6 & 160.1 & 149.4 & 12.6 & 362.9 & 397.0 & 17.9 \\
\hline Naples & 403 & 29.0 & 31.3 & 4.5 & 181.7 & 181.5 & 7.4 & 289.9 & 284.5 & 10.5 \\
\hline Florence & 785 & 31.7 & 31.6 & 3.2 & 207.5 & 206.9 & 5.3 & 321.5 & 320.8 & 7.5 \\
\hline Turin & 392 & 32.0 & 31.8 & 4.5 & 237.7 & 237.7 & 7.5 & 357.6 & 359.6 & 10.6 \\
\hline Varese & 794 & 34.6 & 36.6 & 3.2 & 173.8 & 166.0 & 5.3 & 334.7 & 333.6 & 7.4 \\
\hline \multicolumn{11}{|l|}{ France } \\
\hline South coast & 612 & 37.8 & 30.9 & 3.6 & 235.9 & 274.8 & 6.0 & 231.0 & 245.7 & 8.5 \\
\hline South & 1396 & 50.9 & 49.2 & 2.4 & 228.4 & 226.0 & 4.0 & 256.8 & 259.3 & 5.6 \\
\hline North-west & 622 & 68.8 & 68.8 & 3.6 & 199.3 & 213.8 & 6.0 & 237.5 & 249.7 & 8.4 \\
\hline North-east & 2009 & 55.3 & 56.5 & 2.0 & 222.9 & 220.8 & 3.3 & 244.8 & 248.8 & 4.7 \\
\hline \multicolumn{11}{|l|}{ Germany } \\
\hline Heidelberg & 1087 & 62.1 & 69.3 & 2.8 & 173.4 & 170.1 & 4.6 & 202.1 & 211.3 & 6.4 \\
\hline Potsdam & 1063 & 81.9 & 82.7 & 2.8 & 177.0 & 171.5 & 4.6 & 247.8 & 260.2 & 6.5 \\
\hline \multicolumn{11}{|l|}{ The Netherlands } \\
\hline Bilthoven & 1086 & 81.9 & 84.8 & 2.8 & 135.5 & 132.0 & 4.6 & 157.2 & 168.1 & 6.5 \\
\hline Utrecht & 1874 & 87.2 & 84.4 & 2.1 & 136.5 & 136.1 & 3.5 & 222.2 & 212.8 & 4.9 \\
\hline \multicolumn{11}{|l|}{ United Kingdom } \\
\hline General population & 571 & 73.2 & 71.1 & 3.7 & 173.1 & 173.9 & 6.2 & 172.9 & 172.6 & 8.8 \\
\hline 'Health-conscious' & 197 & 75.7 & 85.5 & 6.4 & 240.9 & 246.2 & 10.6 & 261.7 & 273.0 & 14.9 \\
\hline \multicolumn{11}{|l|}{ Denmark } \\
\hline Copenhagen & 1485 & 66.8 & 70.6 & 2.3 & 148.2 & 152.9 & 3.9 & 186.6 & 180.1 & 5.5 \\
\hline Aarhus & 510 & 72.6 & 71.1 & 4.0 & 145.9 & 148.4 & 6.6 & 239.2 & 233.6 & 9.3 \\
\hline \multicolumn{11}{|l|}{ Sweden } \\
\hline Malmö & 1711 & 86.8 & 82.5 & 2.2 & 128.3 & 133.9 & 3.7 & 162.5 & 150.9 & 5.2 \\
\hline Umeå & 1574 & 90.8 & 91.8 & 2.3 & 125.5 & 125.8 & 3.7 & 164.5 & 159.1 & 5.3 \\
\hline \multicolumn{11}{|l|}{ Norway } \\
\hline South \& East & 1136 & 69.7 & 72.6 & 2.7 & 132.2 & 132.4 & 4.5 & 163.3 & 173.1 & 6.3 \\
\hline North \& West & 662 & 85.0 & 89.7 & 3.5 & 120.1 & 119.9 & 5.8 & 147.0 & 162.1 & 8.2 \\
\hline
\end{tabular}

SEM - standard error of the mean

${ }^{*}$ Adjusted for age and standardised for day of the week and season.

the relative carbohydrate contribution of different food groups. Since a uniform food composition table is not available for Europe and current European food composition tables compute carbohydrates differently ${ }^{30}$, the relative contribution of specific food groups in each EPIC centre could not be examined. Similarly, preliminary information on total energy intake was used when adjusting for energy (energy-adjusted data are not presented). Also, some food groups (e.g. coffee and tea, soups) were not examined in the final analysis, because of their apparent low contribution to carbohydrates. The importance of these foods as carbohydrate sources may be underestimated. Future studies need to examine different types of carbohydrates, as well as the relative contribution of carbohydrates, from various food products across EPIC centres.

The broader food groups in this study may reduce the actual diversity of European food habits, because each food group incorporates a range of foods and food products. For example, 'crispbread' in Nordic countries is commonly based on whole-grain rye ${ }^{46}$, while wheat flour is preferred in southern European countries. Also, salty biscuits and snacks in Italian centres are not only crackers, but also bread dipped in salt and olive oil. The apparent balances, in some centres, between bread and sweet buns, cakes and pies, potatoes, crispbread and breakfast cereal indicate that the food sources of fibre may vary considerably across EPIC centres. No conclusion on differences in fibre sources can be made in this study, because the fibre content of bread and cereal products was not examined. The food group sweet buns, cakes and pies includes cereal- or flour-based items with added sugar, but the relative proportions of sugar, starch, fibre and fat could vary substantially between study centres, depending on the customary use. Similarly, bread is in reality a composite of many kinds made with different 
Table 3e Mean consumption of fruit and vegetable juices, soft drinks, and milk and milk products by women $(n=22924)$ in 27 European Prospective Investigation into Cancer and Nutrition (EPIC) centres

\begin{tabular}{|c|c|c|c|c|c|c|c|c|c|c|}
\hline \multirow[b]{3}{*}{ Country and centre } & \multirow[b]{3}{*}{ Total $n$} & \multicolumn{3}{|c|}{$\begin{array}{l}\text { Fruit \& vegetable juices } \\
\qquad\left(\text { g day }^{-1}\right)\end{array}$} & \multicolumn{3}{|c|}{ Soft drinks (g day ${ }^{-1}$ ) } & \multicolumn{3}{|c|}{ Milk \& milk products $\left(\mathrm{g} \mathrm{day}^{-1}\right)$} \\
\hline & & \multirow[b]{2}{*}{ Crude mean } & \multicolumn{2}{|c|}{ Adjusted* } & \multirow[b]{2}{*}{ Crude mean } & \multicolumn{2}{|c|}{ Adjusted ${ }^{*}$} & \multirow[b]{2}{*}{ Crude mean } & \multicolumn{2}{|c|}{ Adjusted $^{*}$} \\
\hline & & & Mean & SEM & & Mean & SEM & & Mean & SEM \\
\hline \multicolumn{11}{|l|}{ Greece } \\
\hline Greece & 1374 & 41.6 & 49.2 & 4.1 & 28.1 & 35.2 & 4.8 & 151.0 & 146.1 & 6.2 \\
\hline \multicolumn{11}{|l|}{ Spain } \\
\hline Granada & 300 & 36.2 & 37.8 & 8.8 & 67.7 & 77.9 & 10.3 & 363.5 & 366.3 & 13.3 \\
\hline Murcia & 304 & 37.6 & 32.4 & 8.7 & 49.7 & 45.3 & 10.3 & 316.0 & 314.1 & 13.2 \\
\hline Navarra & 271 & 28.2 & 26.5 & 9.2 & 22.9 & 20.3 & 10.9 & 380.6 & 378.4 & 14.0 \\
\hline San Sebastian & 244 & 23.1 & 18.3 & 9.7 & 29.5 & 22.4 & 11.5 & 386.9 & 388.2 & 14.7 \\
\hline Asturias & 324 & 39.4 & 35.6 & 8.5 & 41.3 & 38.2 & 10.0 & 462.5 & 461.6 & 12.8 \\
\hline \multicolumn{11}{|l|}{ Italy } \\
\hline Ragusa & 138 & 9.9 & 4.4 & 13.0 & 43.8 & 28.6 & 15.3 & 117.3 & 116.2 & 19.6 \\
\hline Naples & 403 & 21.6 & 19.0 & 7.6 & 22.3 & 17.6 & 8.9 & 145.0 & 150.7 & 11.4 \\
\hline Florence & 785 & 24.3 & 23.8 & 5.4 & 12.2 & 12.9 & 6.4 & 174.8 & 175.9 & 8.2 \\
\hline Turin & 392 & 28.8 & 26.9 & 7.7 & 27.1 & 28.0 & 9.0 & 154.5 & 152.8 & 11.6 \\
\hline Varese & 794 & 18.5 & 18.9 & 5.4 & 21.9 & 22.5 & 6.4 & 204.2 & 203.7 & 8.2 \\
\hline \multicolumn{11}{|l|}{ France } \\
\hline South coast & 612 & 48.2 & 47.8 & 6.2 & 9.3 & 11.9 & 7.3 & 233.7 & 241.4 & 9.3 \\
\hline South & 1396 & 51.6 & 54.1 & 4.1 & 14.5 & 18.9 & 4.8 & 237.9 & 232.8 & 6.2 \\
\hline North-west & 622 & 56.6 & 63.5 & 6.1 & 8.4 & 12.4 & 7.2 & 238.3 & 235.3 & 9.2 \\
\hline North-east & 2009 & 55.7 & 60.1 & 3.4 & 14.5 & 18.6 & 4.0 & 242.1 & 240.4 & 5.1 \\
\hline \multicolumn{11}{|l|}{ Germany } \\
\hline Heidelberg & 1087 & 175.7 & 164.7 & 4.7 & 68.4 & 57.2 & 5.5 & 205.3 & 207.7 & 7.1 \\
\hline Potsdam & 1063 & 158.2 & 156.0 & 4.7 & 30.4 & 28.5 & 5.5 & 210.8 & 204.0 & 7.1 \\
\hline \multicolumn{11}{|l|}{ The Netherlands } \\
\hline Bilthoven & 1086 & 104.1 & 97.7 & 4.7 & 103.8 & 92.4 & 5.5 & 296.5 & 297.8 & 7.1 \\
\hline Utrecht & 1874 & 100.3 & 104.9 & 3.5 & 68.5 & 73.0 & 4.2 & 390.8 & 386.7 & 5.4 \\
\hline \multicolumn{11}{|l|}{ United Kingdom } \\
\hline General population & 571 & 65.5 & 69.8 & 6.4 & 141.1 & 140.6 & 7.5 & 350.4 & 346.1 & 9.6 \\
\hline 'Health-conscious' & 197 & 94.7 & 82.4 & 10.8 & 103.3 & 101.1 & 12.8 & 220.5 & 195.6 & 16.4 \\
\hline \multicolumn{11}{|l|}{ Denmark } \\
\hline Copenhagen & 1485 & 52.8 & 55.2 & 4.0 & 123.5 & 129.2 & 4.6 & 253.5 & 252.1 & 6.0 \\
\hline Aarhus & 510 & 59.0 & 54.7 & 6.7 & 93.2 & 96.0 & 7.9 & 276.1 & 268.7 & 10.2 \\
\hline \multicolumn{11}{|l|}{ Sweden } \\
\hline Malmö & 1711 & 46.9 & 53.4 & 3.8 & 63.3 & 75.9 & 4.4 & 276.2 & 273.3 & 5.7 \\
\hline Umeå & 1574 & 42.8 & 43.0 & 3.8 & 114.6 & 121.9 & 4.5 & 334.5 & 334.3 & 50 \\
\hline \multicolumn{11}{|l|}{ Norway } \\
\hline South \& East & 1136 & 93.8 & 96.6 & 4.6 & 167.9 & 163.1 & 5.4 & 246.8 & 245.7 & 6.9 \\
\hline North \& West & 662 & 89.2 & 83.5 & 6.0 & 167.7 & 159.1 & 7.0 & 243.4 & 247.6 & 9.0 \\
\hline
\end{tabular}

SEM - standard error of the mean.

*Adjusted for age and standardised for day of the week and season.

cereals, types of flour and bread-making procedures. However, if all differences were accounted for, a huge amount of data and many models would be required, which is beyond the scope of this paper.

Other researchers have also reported higher intakes of sugar-rich food products in northern compared with southern Europe ${ }^{44}$. Such observations may have important implications for cross-cultural comparisons and the interpretation of diet-disease relationships. When the percentage of dietary fat is reduced, intakes of foods with low micronutrient density and rich in added sugars tend to increase, rather than foods rich in starch and dietary fibre, i.e. the so-called fat and sugar seesaw ${ }^{47-51}$. Populations of southern Europe, where vegetables and fruits are traditionally consumed in larger amounts, may be less vulnerable to such seesaw patterns. However, a French study indicates that individuals with high sugar intakes (compared with those with low intakes) are younger, leaner and have more varied diets, but also have low intakes of fruits and vegetables ${ }^{51}$.

The consumption gradient of milk among adults across European populations is believed to result from genetic adaptation $^{52,53}$, related to the prevalence of lactose maldigestion being very low in northern Europe (i.e. 1$3 \%$ in Denmark and Sweden), moderate in central Europe (i.e. 8-22\% in Germany) and high in the south (i.e. 50$72 \%$ in Italy $)^{52}$. However, milk consumption is high in the Spanish centres in this study. Other studies indicate that milk consumption has increased in Spain during the last three decades ${ }^{43}$ and it may be that lactose maldigestion is less common in Spain than in other southern European populations $^{52}$. Also, moderate amounts of milk may be tolerated well by individuals with lactose maldigestion ${ }^{53}$. Cheese is not included in the milk group because of its 
Table 3f Mean consumption of sugar and jam, sweets, and chocolates by women ( $n=22924)$ in 27 European Prospective Investigation into Cancer and Nutrition (EPIC) centres

\begin{tabular}{|c|c|c|c|c|c|c|c|c|c|c|}
\hline \multirow[b]{3}{*}{ Country and centre } & \multirow[b]{3}{*}{ Total $n$} & \multicolumn{3}{|c|}{ Sugar \& jam $\left(\right.$ g day $\left.^{-1}\right)$} & \multicolumn{3}{|c|}{ Sweets (g day ${ }^{-1}$ ) } & \multicolumn{3}{|c|}{ Chocolates $\left(\mathrm{g} \mathrm{day}^{-1}\right.$ ) } \\
\hline & & \multirow[b]{2}{*}{ Crude mean } & \multicolumn{2}{|c|}{ Adjusted $^{*}$} & \multirow[b]{2}{*}{ Crude mean } & \multicolumn{2}{|c|}{ Adjusted $^{*}$} & \multirow[b]{2}{*}{ Crude mean } & \multicolumn{2}{|c|}{ Adjusted $^{*}$} \\
\hline & & & Mean & SEM & & Mean & SEM & & Mean & SEM \\
\hline \multicolumn{11}{|l|}{ Greece } \\
\hline Greece & 1374 & 9.8 & 10.2 & 0.6 & 3.1 & 3.1 & 0.5 & 2.3 & 2.5 & 0.5 \\
\hline \multicolumn{11}{|l|}{ Spain } \\
\hline Granada & 300 & 12.2 & 12.4 & 1.4 & 2.3 & 3.1 & 1.1 & 2.1 & 1.4 & 1.1 \\
\hline Murcia & 304 & 12.0 & 12.2 & 1.4 & 2.3 & 2.2 & 1.1 & 2.0 & 1.6 & 1.0 \\
\hline Navarra & 271 & 14.6 & 14.5 & 1.4 & 3.5 & 3.5 & 1.1 & 2.3 & 2.1 & 1.1 \\
\hline San Sebastian & 244 & 18.9 & 19.2 & 1.5 & 3.9 & 3.7 & 1.2 & 3.2 & 3.1 & 1.2 \\
\hline Asturias & 324 & 15.7 & 16.1 & 1.3 & 3.1 & 2.8 & 1.0 & 4.0 & 4.2 & 1.0 \\
\hline \multicolumn{11}{|l|}{ Italy } \\
\hline Ragusa & 138 & 8.9 & 11.8 & 2.0 & 0.2 & 0 & 1.6 & 4.2 & 8.1 & 1.6 \\
\hline Naples & 403 & 14.0 & 13.5 & 1.2 & 2.2 & 1.4 & 0.9 & 3.6 & 3.1 & 0.9 \\
\hline Florence & 785 & 10.2 & 9.9 & 0.8 & 0.6 & 0.6 & 0.7 & 2.8 & 2.6 & 0.7 \\
\hline Turin & 392 & 14.1 & 14.2 & 1.2 & 2.2 & 2.2 & 0.9 & 2.6 & 2.7 & 0.9 \\
\hline Varese & 794 & 15.0 & 14.9 & 0.8 & 2.2 & 2.6 & 0.7 & 2.5 & 2.6 & 6.4 \\
\hline \multicolumn{11}{|l|}{ France } \\
\hline South coast & 612 & 19.5 & 18.1 & 1.0 & 2.4 & 2.8 & 0.8 & 7.6 & 7.4 & 0.7 \\
\hline South & 1396 & 21.0 & 20.7 & 0.6 & 2.8 & 2.7 & 0.5 & 6.1 & 5.9 & 0.5 \\
\hline North-west & 622 & 20.4 & 19.5 & 0.9 & 1.8 & 2.6 & 0.7 & 6.3 & 6.5 & 0.7 \\
\hline North-east & 2009 & 19.0 & 19.0 & 0.5 & 3.0 & 3.3 & 0.4 & 8.1 & 7.8 & 0.4 \\
\hline \multicolumn{11}{|l|}{ Germany } \\
\hline Heidelberg & 1087 & 15.4 & 16.2 & 0.7 & 3.3 & 2.8 & 0.6 & 8.6 & 8.0 & 0.6 \\
\hline Potsdam & 1063 & 14.3 & 14.8 & 0.7 & 3.1 & 3.1 & 0.6 & 7.4 & 7.6 & 0.6 \\
\hline \multicolumn{11}{|l|}{ The Netherlands } \\
\hline Bilthoven & 1086 & 17.3 & 17.7 & 0.7 & 8.8 & 8.3 & 0.6 & 10.1 & 9.3 & 0.6 \\
\hline Utrecht & 1874 & 15.3 & 15.0 & 0.6 & 9.1 & 9.4 & 0.4 & 7.8 & 8.4 & 0.4 \\
\hline \multicolumn{11}{|l|}{ United Kingdom } \\
\hline General population & 571 & 13.5 & 13.9 & 1.0 & 3.0 & 3.2 & 0.8 & 10.6 & 9.9 & 0.8 \\
\hline 'Health-conscious' & 197 & 15.1 & 14.1 & 1.7 & 4.3 & 4.2 & 1.3 & 9.8 & 8.2 & 1.3 \\
\hline \multicolumn{11}{|l|}{ Denmark } \\
\hline Copenhagen & 1485 & 14.5 & 15.1 & 0.6 & 3.9 & 3.8 & 0.5 & 7.0 & 7.5 & 4.7 \\
\hline Aarhus & 510 & 14.2 & 14.0 & 1.0 & 8.7 & 9.0 & 0.8 & 8.2 & 7.8 & 0.8 \\
\hline \multicolumn{11}{|l|}{ Sweden } \\
\hline Malmö & 1711 & 16.5 & 16.1 & 0.6 & 7.6 & 8.3 & 0.5 & 7.7 & 8.5 & 0.5 \\
\hline Umeå & 1574 & 21.6 & 21.4 & 0.6 & 6.0 & 6.0 & 0.5 & 4.8 & 4.9 & 0.5 \\
\hline \multicolumn{11}{|l|}{ Norway } \\
\hline South \& East & 1136 & 17.6 & 18.7 & 0.7 & 3.0 & 2.6 & 0.6 & 10.7 & 9.8 & 0.6 \\
\hline North \& West & 662 & 21.2 & 21.6 & 0.9 & 2.7 & 2.5 & 0.7 & 8.8 & 8.4 & 0.7 \\
\hline
\end{tabular}

SEM - standard error of the mean

${ }^{*}$ Adjusted for age and standardised for day of the week and season.

negligible carbohydrate content. In Norwegian diets, however, $1 \%$ of total carbohydrate intake comes from cheese $^{54}$, because 'brown' cheese (made from whey and with a high content of lactose) is commonly eaten. But the percentage is not high enough to count as a major carbohydrate source in this study.

Men consume, overall, higher amounts of vegetables and legumes, bread, soft drinks, potatoes, pasta and rice, breakfast cereal, and sugar and jam. Since no adjustment was made for energy intake differences between gender groups (but analysis was stratified by gender), the higher intakes of these foods are most likely explained by higher energy needs in men. Both gender groups consume sweet buns, cakes and pies, sweet biscuits, crispbread, salty biscuits and snacks, chocolates, sweets, milk and milk products, and fruit and vegetable juices in equal amounts. This suggests that these foods take up larger proportions of the diets of women. In addition, fruit consumption is reported in a larger percentage of dietary recalls in women. Other studies report similar gender differences both in food preferences ${ }^{55}$ and intakes ${ }^{56}$.

The study samples for the EPIC calibration study were selected randomly from each sub-study cohort ${ }^{27}$. However, the definition and recruitment of sub-cohorts varied by study centre (e.g. France and Norway recruited only women; some centres used specific sub-populations) and the findings should therefore not be extrapolated to the general populations of each region. In addition, since this study did not adjust for differences in socio-economic and lifestyle factors, it is plausible that food consumption differences observed between cohorts depend partly on socio-economic or lifestyle differences. Several studies have described that lifestyle behaviours and sociodemographic factors co-vary with healthy food choices 


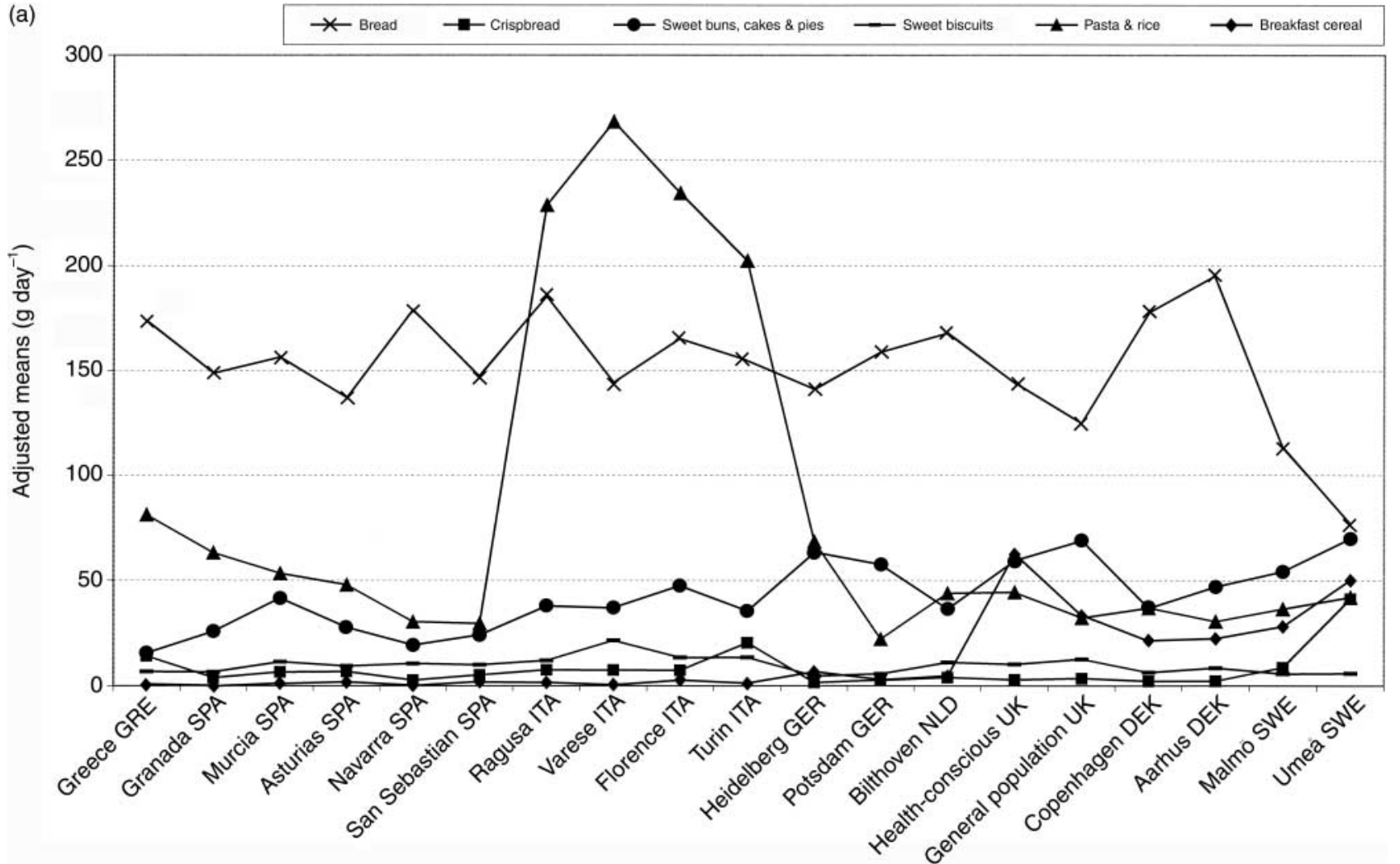

Fig. 1a Consumption of bread, crispbread, sweet buns, cakes and pies, sweet biscuits, pasta and rice, and breakfast cereal by men in 19 European Prospective Investigation into Cancer and Nutrition (EPIC) centres. Abbreviations: GRE - Greece; SPA - Spain; ITA Italy; GER - Germany; NLD - The Netherlands; UK - United Kingdom; DEK - Denmark; SWE - Sweden

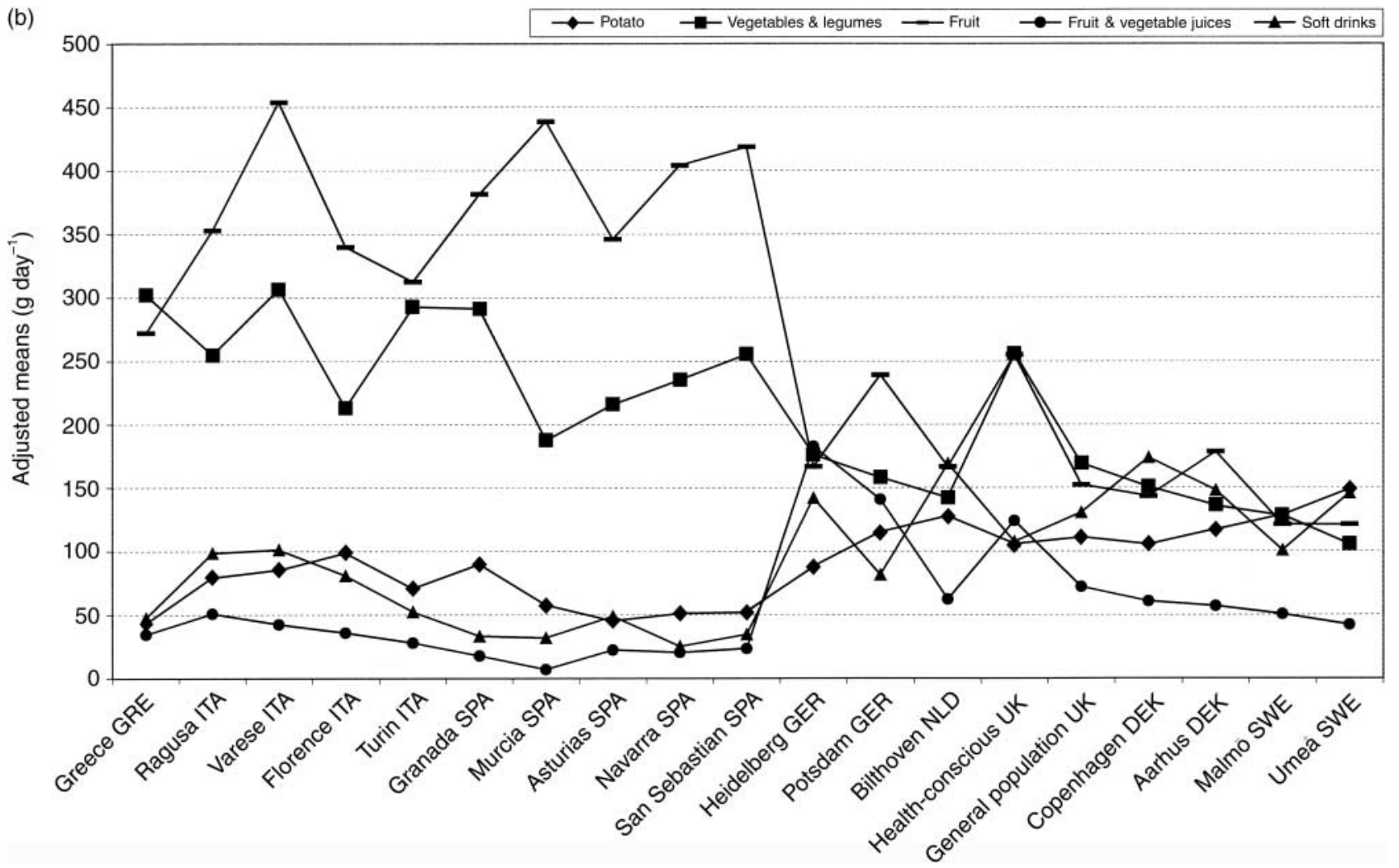

Fig. 1b Consumption of potato, vegetables and legumes, fruit, fruit and vegetable juices, and soft drinks by men in 19 European Prospective Investigation into Cancer and Nutrition (EPIC) centres. Abbreviations: GRE - Greece; SPA - Spain; ITA - Italy; GER Germany; NLD - The Netherlands; UK - United Kingdom; DEK - Denmark; SWE - Sweden 


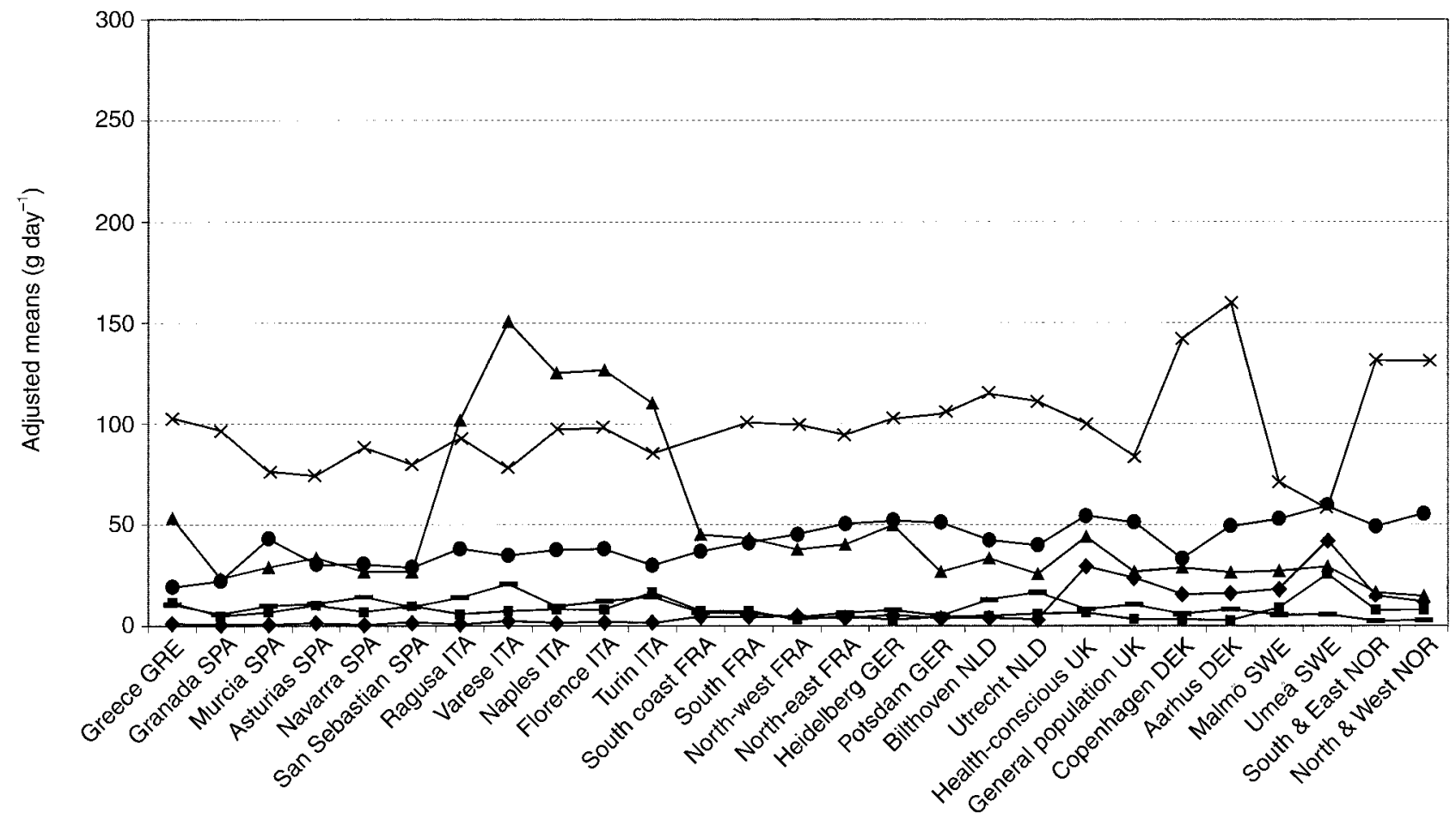

Fig. 2a Consumption of bread, crispbread, sweet buns, cakes and pies, sweet biscuits, pasta and rice, and breakfast cereal by women in 27 European Prospective Investigation into Cancer and Nutrition (EPIC) centres. Abbreviations: GRE - Greece; SPA - Spain; ITA Italy; FRA - France; GER - Germany; NLD - The Netherlands; UK - United Kingdom; DEK - Denmark; SWE - Sweden; NOR - Norway

(b)

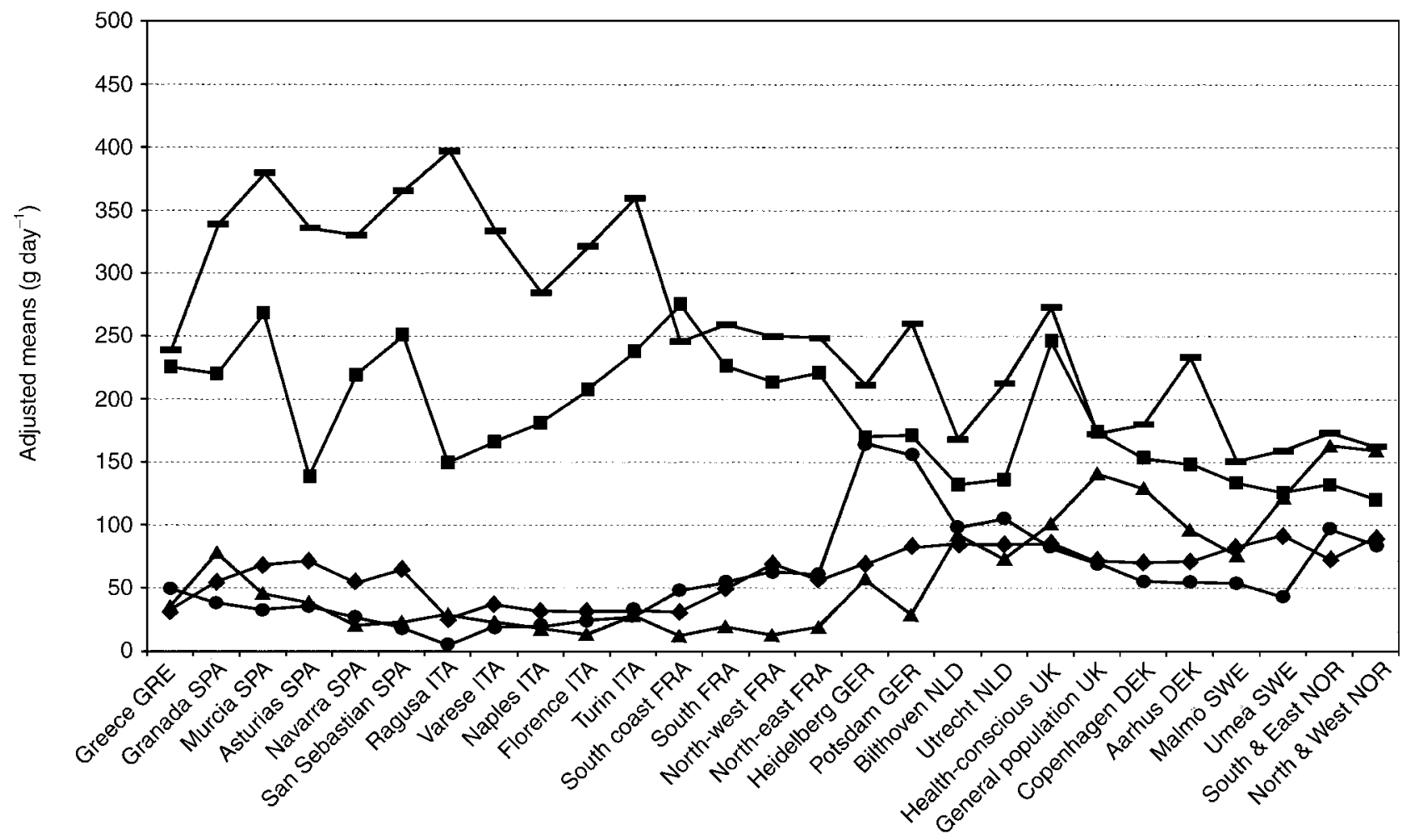

Fig. 2b Consumption of potato, vegetables and legumes, fruit, fruit and vegetable juices, and soft drinks by women in 27 European Prospective Investigation into Cancer and Nutrition (EPIC) centres. Abbreviations: GRE - Greece; SPA - Spain; ITA - Italy; FRA - France; GER - Germany; NLD - The Netherlands; UK - United Kingdom; DEK - Denmark; SWE - Sweden; NOR - Norway 
such as fruit and vegetable intakes ${ }^{57-59}$. For instance, reports from Denmark and Sweden indicate that alcohol use (especially wine) is positively related to fruit and vegetable consumption ${ }^{60,61}$. Such relations are not found in Italy ${ }^{62}$, however. Because clear consumption gradients are visible across EPIC centres in this study, one might speculate that the associations between food sources of carbohydrates and potential confounders are dissimilar. This notion is supported by a review of research in 15 European countries that concluded that fruit and vegetable consumption was higher in population groups with lower education in some southern European countries ${ }^{63}$. However, recent studies across EPIC centres in both Spain and Italy indicate that vegetable and fruit consumption is indeed higher among those with higher education $^{64-66}$. In addition, although many regional food consumption differences have been removed by technical developments and improved communications, some still exist. For instance, fruit consumption is high in Ragusa (Italy) because Sicily is a major fruit-producing region. Also, differences in the cost of bread may explain the north-south gradient in bread consumption seen in Italy (less than $€ 1$ per $\mathrm{kg}$ in the south, more than $€ 3$ in the north).

To conclude, this study supports the established idea that the choice of carbohydrate-rich foods in northern Europe is different from that in the Mediterranean region. Due to potential differences in confounders across geographically and culturally diverse populations, researchers need to consider carefully the intake ranges for all food choices and non-dietary confounders when comparing and interpreting diet-disease relations across centres participating in the EPIC study.

\section{Acknowledgements}

The work described in this paper was carried out with financial support of the 'Europe Against Cancer' Programme of the European Commission (SANCO); Ligue contre le Cancer (France); Société $3 \mathrm{M}$ (France); Mutuelle Générale de l'Education Nationale; Institut National de la Santé et de la Recherche Médicale (INSERM); Institute Gustave Roussy; German Cancer Aid; German Cancer Research Centre; German Federal Ministry of Education and Research; Danish Cancer Society; Health Research Fund (FIS) of the Spanish Ministry of Health; the Spanish Regional Governments of Andalucia, Asturias, Basque Country, Murcia and Navarra; Cancer Research UK; Medical Research Council, UK; Stroke Association, UK; British Heart Foundation; Department of Health, UK; Food Standards Agency, UK; Wellcome Trust, UK; Greek Ministry of Health; Greek Ministry of Education; Italian Association for Research on Cancer; Italian National Research Council; Dutch Ministry of Public Health, Welfare and Sports; Dutch Prevention Funds; LK Research Funds; Dutch ZON (Zorg Onderzoek Nederland); World Cancer
Research Fund; Swedish Cancer Society; Swedish Scientific Council; Regional Government of Skane, Sweden; Norwegian Cancer Society; Norwegian Research Council. Partial support for the publication of this supplement was provided by the Centre de Recherche et d'Information Nutritionnelles (CERIN).

In addition, we wish to thank all study participants for their co-operation and all interviewers who participated in the fieldwork studies in each EPIC centre.

\section{References}

1 Freudenheim JL, Krogh V, D'Amicis A, Scaccini C, Sette S, Ferro-Lucci A, et al. Food sources of nutrients in the diet of elderly Italians: I. Macronutrients and lipids. Int. J. Epidemiol. 1993; 22: 855-68.

2 World Cancer Research Fund/American Institute for Cancer Research (WCRF/AICR). Food, Nutrition and the Prevention of Cancer: A Global Perspective. Washington, DC: WCRF/AICR, 1997.

3 Trichopoulou A, Vasilopoulou E. Nutritional composition and flavonoid content of edible wild greens and green pies: a potential rich source of antioxidant nutrients in the Mediterranean diet. Food Chem. 2000; 70: 319-23.

4 Messina MJ, Persky V, Setchell KDR, Barnes S. Soy intake and cancer risk: a review of the in vitro and in vivo data. Nutr. Cancer 1994; 21: 113-31.

5 Thompson L, Robb P, Serraino M, Cheung F. Mammalian lignan production from various foods. Nutr. Cancer 1991; 16: $43-52$.

6 Adlercreutz H. Phytoestrogens: epidemiology and a possible role in cancer protection. Environ. Health Perspect. 1995; 103: $103-12$.

7 Liljeberg H, Björck I. Effects of a low-glycemic index spaghetti meal on glucose tolerance and lipidemia at a subsequent meal in healthy subjects. Eur.J. Clin. Nutr. 2000; 54: $24-8$.

8 Liljeberg H, Björck I. Delayed gastric emptying rate may explain improved glycaemia in healthy subjects to a starchy meal with added vinegar. Eur. J. Clin. Nutr. 1998; 52: $368-71$

9 Martin L, Dumon H, Lecannu G, Champ M. Potato and highamylose maize starches are not equivalent producers of butyrate for the colonic mucosa. Br. J. Nutr. 2000; 84: 689-96.

10 Salmeron J, Manson J-AE, Stampfer MJ, Colditz GA, Wing AL, Willet WC. Dietary fiber, glycemic load, and risk of noninsulin-dependent diabetes mellitus in women. J. Am. Med. Assoc. 1997; 277: 472-7.

11 Salmeron J, Ascherio A, Rimm E, Colditz G, Spiegelman D, Jenkins D, et al. Dietary fiber, glycemic load, and risk of NIDDM in men. Diabetes Care 1997; 20: 545-50.

12 Agus M, Swain J, Larson C, Eckert E, Ludwig D. Dietary composition and physiologic adaptations to energy restriction. Am. J. Clin. Nutr. 2000; 71: 901-7.

13 Kaaks R. Nutrition, hormones and breast cancer: is insulin the missing link? Cancer Causes Control 1996; 7: 605-25.

14 La Vecchia C, Negri E, Decarli A, Franceschi S. Diabetes mellitus and colorectal cancer risk. Cancer Epidemiol. Biomark. Prev. 1997; 6: 1007-10.

15 Kono S, Honjo S, Todoroki I, Nishiwaki M, Hamada H, Nishikawa $\mathrm{H}$, et al. Glucose intolerance and adenomas of the sigmoid colon in Japanese men. Cancer Causes Control 1998; 9: 441-6.

16 Hu F, Manson J, Liu S, Hunter D, Colditz G, Michels K, et al. Prospective study of adult onset diabetes mellitus (type 2) 
and risk of colorectal cancer in women. J. Natl. Cancer Inst. 1999; 91: 542-7.

17 Nilsen T, Vatten L. Prospective study of colorectal cancer risk and physical activity, diabetes, blood glucose and BMI: exploring the hyperinsulinemia hypothesis. $\mathrm{Br}$. J. Cancer 2001; 84: 417-22

18 Phillips J, Muir J, Birkett A, Lu Z, Jones G, O'Dea K, et al. Effect of resistant starch on fecal bulk and fermentationdependent events in humans. Am. J. Clin. Nutr. 1995; 62: 121-30.

19 Jenkins D, Vuksan V, Kendall C, Wursch P, Jeffcoat R, Waring $S$, et al. Physiological effects of resistant starches on fecal bulk, short chain fatty acids, blood lipids and glycemic index. J. Am. Coll. Nutr. 1998; 17: 609-16.

20 Hylla S, Gostner A, Dusel G, Anger H, Bartram H, Christl S, et al. Effects of resistant starch on the colon in healthy volunteers: possible implications for cancer prevention. $\mathrm{Am}$. J. Clin. Nutr. 1998; 67: 136-42.

21 Hald MT, Vogel U, Dragsted L, Loft S, Wallin $\mathrm{H}$. Characterization of sugar-induced mutations in the cIl gene in the colon of Big Blue rats. Paper presented at Danish Cancer Society Symposium, Nutrition and Cancer, 26-29 August 2001.

22 Slattery ML, Curtin K, Anderson K, Ma KN, Edwards S, Leppert $\mathrm{M}$, et al. Associations between dietary intake and $\mathrm{Ki}$ ras mutations in colon tumors: a population-based study. Cancer Res. 2000; 60: 6935-41.

23 Southgate D. The role of dietary fibre in the diet. J. Roy. Soc. Health 1990; 110: 174-176.

24 Greenwald P, Clifford C, Milner J. Diet and cancer prevention. Eur. J. Cancer 2001; 37: 948-965.

25 McCann J. Obesity, cancer links prompts new recommendations. J. Natl. Cancer Inst. 2001; 93: 901-902.

26 Riboli E, Kaaks R. The EPIC Project: rationale and study design. Int. J. Epidemiol. 2001; 26: S6-S14.

27 Slimani N, Kaaks R, Ferrari P, Casagrande C, Clavel F, Lotze $\mathrm{G}$, et al. European Prospective Investigation into Cancer and Nutrition (EPIC) calibration study: rationale, design and population characteristics. Public Health Nutr. 2002; 5(6B): $1125-45$.

28 Slimani N, Ferrari P, Ocké M, Welch A, Boeing H, Liere M, et al. Standardization of the 24-hour recall calibration method used in the European Prospective Investigation into Cancer and Nutrition (EPIC): general concepts and preliminary results. Eur. J. Clin. Nutr. 2000; 54: 900-17.

29 Slimani N, Deharveng G, Charrondière R, van Kappel A, Ocké M, Welch A, et al. Structure of the standardized computerized 24-h diet recall interview used as reference method in the 22 centers participating in the EPIC project. European Prospective Investigation into Cancer and Nutrition. Comput. Meth. Programs Biomed. 1999; 58: 251-66.

30 Deharveng G, Charrondière UR, Slimani N, Southgate DAT, Riboli E. Comparisons of nutrients in the food composition tables available in the nine European countries participating in EPIC. Eur. J. Clin. Nutr. 1999; 53: 60-79.

31 Norusis MJ. SPSS for Windows Professional Statistics, Release 6.O. Chicago, IL: SPSS Inc., 1993.

32 Helsing E. Trends in fat consumption in Europe and their influence on the Mediterranean diet. Eur.J. Clin. Nutr. 1993 47: S4-12

33 Cruz A. Dietary habits and nutritional status in adolescents over Europe - Southern Europe. Eur. J. Clin. Nutr. 2000; 54: S29-35.

34 Kushi L, Lenart E, Willett W. Health implications of Mediterranean diets in light of contemporary knowledge. 1. Plant foods and dairy products. Am.J. Clin. Nutr. 1995; 61 1407S-15S.

35 Kushi L, Lenart E, Willett W. Health implications of Mediterranean diets in light of contemporary knowledge.
2. Meat, wine, fats, and oil. Am. J. Clin. Nutr. 1995; 61 1416S-27S.

36 Keys A. Coronary heart disease in seven countries. Circulation 1970; 41(Suppl. 1): 1-211.

37 Trichopoulou A, Vasilopoulou E, Lagiou A. Mediterranean diet and coronary heart disease: are antioxidants critical? Nutr. Rev. 1999; 57: 253-5.

38 Tavani A, LaVecchia C. Fruit and vegetable consumption and cancer risk in a Mediterranean population. Am.J. Clin. Nutr. 1995; 61: 1374S-7S.

39 Trichopoulou A, Lagiou P, Kuper H, Trichopoulos D. Cancer and Mediterranean dietary traditions. Cancer Epidemiol. Biomark. Prev. 2000; 9: 869-73.

40 Steinmetz K, Potter J. Vegetables, fruits and cancer. I. Epidemiology. Cancer Causes Control 1991; 2: 325-57.

41 Ness AR, Powles JW. Fruit and vegetables, and cardiovascular disease: a review. Int. J. Epidemiol. 1997; 26: 1-13.

42 Law M, Morris J. By how much does fruit and vegetable consumption reduce the risk of ischaemic heart disease? Eur. J. Clin. Nutr. 1998; 52: 549-56.

43 Serra-Majem L, Ribas L, Tresserras R, Ngo J, Salleras J. How could changes in diet explain changes in coronary heart disease mortality in Spain? The Spanish paradox. Am.J. Clin. Nutr. 1995; 61: 1351S-9S.

44 Holdsworth M, Gerber M, Haslam C, Scali J, Beardsworth A, Avallone $\mathrm{M}$, et al. A comparison of dietary behaviour in Central England and a French Mediterranean region. Eur. J. Clin. Nutr. 2000; 54: 530-9.

45 Roos G, Prättälä R. Disparities in Food Habits. Review of Research in 15 European Countries. Publications of the National Public Health Institute. FAIR-97-3096 Disparities Group (tasks 4 and 5) (B24). Helsinki, Finland: KTLNational Public Health Institute, 1999.

46 Adlercreutz H. Epidemiology of phytoestrogens. Baillières Best Pract. Clin. Endocrinol. Metab. 1998; 12: 605-23.

47 Gibson S. Are high-fat, high-sugar foods and diets conducive to obesity? Int. J. Food Sci. Nutr. 1996; 47: 405-15.

48 Macdiarmid J, Cade J, Blundell J. High and low fat consumers, their macronutrient intake and body mass index: further analysis of the National Diet and Nutrition Survey of British Adults. Eur. J. Clin. Nutr. 1996; 50: 505-12.

49 Macdiarmid J, Vail A, Cade J, Blundell J. The sugar-fat relationship revisited: differences in consumption between men and women of varying BMI. Int. J. Obes. Relat. Metab. Disord. 1998; 22: 1053-61.

50 Boulton-Smith C, Woodward M. Dietary composition and fat to sugar ratios in relation to obesity. Int. J. Obes. Relat. Disord. 1994; 18: 820-8.

51 Drewnowski A, Henderson S, Shore A, Fischler C, Preziosi P, Hercberg S. The fat-sucrose seesaw in relation to age and dietary variety of French adults. Obes. Res. 1997; 5: 511-8.

52 Gudmand-Höyer E, Skovberg H. Disaccharide digestion and maldigestion. Scand. J. Gastroenterol. 1996; 31: 111-21.

53 Suarez F, Savaiano D, Levitt M. A comparison of symptoms after the consumption of milk or lactose-hydrolyzed milk by people with self-reported severe lactose intolerance. $N$. Engl. J. Med. 1995; 333: 1-4.

54 Norkost 1997. Landsomfattende kostholdsundersökelse blant menn og kvinner i alderen 16- 79 år. Rapport 2/1999. Oslo: Statens råd for ernaering og fysisk aktivitet, 1999.

55 O'Doherty Jensen K, Holm L. Preferences, quantities and concerns: socio-cultural perspectives on the gendered consumption of foods. Eur. J. Clin. Nutr. 1999; 53: 351-9.

56 Beer-Borst S, Hercberg S, Morabia A, Bernstein M, Galan P, Galasso R, et al. Dietary patterns in six European populations: results from EURALIM, a collaborative European data harmonization and information campaign. Eur. J. Clin. Nutr. 2000; 54: 253-62.

57 Patterson RE, Haines PS, Popkin BM. Health lifestyle patterns of US adults. Prev. Med. 1994; 23: 453-60. 
58 Johansson L, Frost Andersen L. Who eats 5 a day? Intake of fruits and vegetables among Norwegians in relation to gender and lifestyle. J. Am. Diet. Assoc. 1998; 98: 689-91.

59 Irala-Estevez J, Groth M, Johansson L, Oltersdorf U, Prattala R, Martinez-Gonzalez M. A systematic review of socioeconomic differences in food habits in Europe: consumption of fruit and vegetables. Eur. J. Clin. Nutr. 2000; 54: 706-14.

60 Tjönneland A, Grönbeck M, Stripp C, Overvad K. Wine intake and diet in a random sample of 48763 Danish men and women. Am. J. Clin. Nutr. 1999; 69: 49-54.

61 Wallstrom P, Wirfält E, Janzon L, Mattisson I, Elmstahl S, Johansson $\mathrm{U}$, et al. Fruit and vegetable consumption in relation to risk factors for cancer: a report from the Malmö Diet and Cancer Study. Public Health Nutr. 2000; 3: 263-71.

62 Chatenoud L, Negri E, Vecchia C, Volpato O, Franceschi S. Wine drinking and diet in Italy. Eur. J. Clin. Nutr. 2000; 54: 177-9.
63 Roos G, Johansson L, Kasmel A, Klumbiene J, Prattala R. Disparities in vegetable and fruit consumption: European cases from the north to the south. Public Health Nutr. 2001; 4: $35-43$.

64 Agudo A, Pera G. Vegetable and fruit consumption associated with anthropometric, dietary and lifestyle factors in Spain. EPIC Group of Spain. European Prospective Investigation into Cancer. Public Health Nutr. 1991; 2: 263-71.

65 Agudo A, Amiano P, Barcos A, Barricarte A, Beguiristain JM, Chirlaque MD, et al. Dietary intake of vegetables and fruits among adults in five regions of Spain. EPIC Group of Spain. European Prospective Investigation into Cancer and Nutrition. Eur. J. Clin. Nutr. 1991; 53: 174-80.

66 Pala V, Berrino F, Vineis P, Palli D, Celentano E, Tumino R. How vegetables are eaten in Italian EPIC centres: still setting a good example? Paper presented at European Conference on Nutrition and Cancer, 21-24 June 2001. 